\title{
Dual functions of angiopoietin-like protein 2 signaling in tumor progression and anti-tumor immunity
}

\author{
Haruki Horiguchi, ${ }^{1,2}$ Tsuyoshi Kadomatsu, ${ }^{1,3}$ Ryoma Kurahashi, ${ }^{1,4}$ Chiaki Hara, ${ }^{1,4}$ Keishi Miyata, ${ }^{1,3}$ \\ Masaya Baba, ${ }^{5}$ Hironobu Osumi, ${ }^{1,6}$ Kazutoyo Terada, ${ }^{1,3}$ Kimi Araki, $^{3,7}$ Toshiyuki Takai, $^{8}$ \\ Tomomi Kamba, ${ }^{4}$ W. Marston Linehan, ${ }^{9}$ Toshiro Moroishi, ${ }^{3,10,11}$ and Yuichi Oike ${ }^{1,3,12}$ \\ ${ }^{1}$ Department of Molecular Genetics, Graduate school of Medical science, Kumamoto University, Kumamoto 860-8556, Japan; \\ ${ }^{2}$ Institute of Resource Development and Analysis, Kumamoto University, Kumamoto 860-0811, Japan; ${ }^{3}$ Center for Metabolic \\ Regulation of Healthy Aging (CMHA), Graduate School of Medical Sciences, Kumamoto University, Kumamoto 860-8556, Japan; \\ ${ }^{4}$ Department of Urology, Graduate school of Medical science, Kumamoto University, Chuo-ku, Kumamoto 860-8556, Japan; \\ ${ }^{5}$ International Research Center for Medical Sciences (IRCMS), Kumamoto University, Kumamoto 860-0811, Japan; ${ }^{6}$ Department of \\ Thoracic Surgery, Graduate school of Medical science, Kumamoto University, Kumamoto 860-8556, Japan; ${ }^{7}$ Division of \\ Developmental Genetics, Institute of Resource Development and Analysis, Kumamoto University, Kumamoto 860-0811, Japan \\ ${ }^{8}$ Department of Experimental Immunology, Institute of Development, Aging and Cancer, Tohoku University, Sendai 980-8575, \\ Japan; ${ }^{9}$ Urologic Oncology Branch, Center for Cancer Research, National Cancer Institute, National Institutes of Health, Bethesda, \\ Maryland 20892, USA; ${ }^{10}$ Department of Molecular Enzymology, Faculty of Life sciences, Kumamoto University, Kumamoto \\ 860-8556, Japan; ${ }^{11}$ Precursory Research for Embryonic Science and Technology (PRESTO), Japan Science and Technology Agency \\ (JST), Kawaguchi 332-0012, Japan; ${ }^{12}$ Core Research for Evolutional Science and Technology (CREST), Japan Agency for Medical \\ Research and Development (AMED), Tokyo 100-0004, Japan
}

Angiopoietin-like protein 2 (ANGPTL2) is a secreted glycoprotein homologous to angiopoietins. Previous studies suggest that tumor cell-derived ANGPTL2 has tumor-promoting function. Here, we conducted mechanistic analysis comparing ANGPTL2 function in cancer progression in a murine syngeneic model of melanoma and a mouse model of translocation renal cell carcinoma (tRCC). ANGPTL2 deficiency in tumor cells slowed tRCC progression, supporting a tumor-promoting role. However, systemic ablation of ANGPTL2 accelerated tRCC progression, supporting a tumor-suppressing role. The syngeneic model also demonstrated a tumor-suppressing role of ANGPTL2 in host tumor microenvironmental cells. Furthermore, the syngeneic model showed that PDGFRa fibroblasts in the tumor microenvironment express abundant ANGPTL2 and contribute to tumor suppression. Moreover, host ANGPTL2 facilitates $\mathrm{CD8}^{+} \mathrm{T}$-cell cross-priming and enhances anti-tumor immune responses. Importantly, ANGPTL2 activates dendritic cells through PIR-B-NOTCH signaling and enhances tumor vaccine efficacy. Our study provides strong evidence that ANGPTL2 can function in either tumor promotion or suppression, depending on what cell type it is expressed in.

[Keywords: ANGPTL2; cancer immunity; dendritic cell; PirB]

Supplemental material is available for this article.

Received May 31, 2019; revised version accepted October 7, 2019.

The tumor microenvironment consists of tumor cells and various types of stromal cells, such as immune cells, fibroblasts, and vascular cells (Balkwill et al. 2012). Tumor cells and stromal cells secrete numerous signaling molecules, such as cytokines, chemokines, and growth factors, many of which contribute to tumor progression by promoting tumor growth and tumor cell survival, metastasis, and chemoresistance (Hanahan and Coussens 2012; Binnewies et al. 2018; Emon et al. 2018). However, some

Corresponding authors: oike@gpo.kumamoto-u.ac.jp, tkado@gpo.kumam oto-u.ac.jp

Article is online at http://www.genesdev.org/cgi/doi/10.1101/gad.329417. 119. signaling molecules, such as transforming growth factor$\beta$ (TGF- $\beta$ ), reportedly function not only in tumor progression but also in tumor suppression, depending on context (Massagué 2008; Lebrun 2012). How those factors mediate dual functions is complex and not well understood.

Previously, we and others identified a family of secretory proteins structurally similar to angiopoietin designated angiopoietin-like proteins (ANGPTLs) (Oike et al.

(C) 2019 Horiguchi et al. This article is distributed exclusively by Cold Spring Harbor Laboratory Press for the first six months after the full-issue publication date (see http://genesdev.cshlp.org/site/misc/terms.xhtml). After six months, it is available under a Creative Commons License (Attribution-NonCommercial 4.0 International), as described at http://creativecommons.org/licenses/by-nc/4.0/. 
2003; Hato et al. 2008). We also reported that one of those proteins, ANGPTL2, contributes to maintenance of tissue homeostasis by facilitating tissue repair (Kubota et al. 2005), while excess ANGPTL2 signaling leads to chronic inflammation and irreversible tissue remodeling, promoting development and progression of diseases as diverse as cancer (Tabata et al. 2009; Kadomatsu et al. 2014). Tumor cell-derived ANGPTL2 promotes tumor cell migration and invasion by activating downstream signaling via integrin $\alpha 5 \beta 1$, accelerating metastasis in lung and breast cancers and osteosarcoma (Endo et al. 2012; Odagiri et al. 2014; Masuda et al. 2015). These findings suggest that cell-autonomous ANGPTL2 signaling in tumor cells functions in tumor progression. However, a previous study reported that ANGPTL2 protein levels in tumor tissues are inversely correlated with patient survival in the case of ovarian cancer (Kikuchi et al. 2008). These findings suggest that ANGPTL2 signaling contributes to tumor suppression in some contexts.

Here, we report that tumor stroma-derived ANGPTL2 contributes to tumor suppression by enhancing dendritic cell-mediated $\mathrm{CD} 8{ }^{+} \mathrm{T}$ cell anti-tumor immune responses. By contrast, we confirm that ANGPTL2 plays a tumorpromoting role when expressed in cancer cells. Our findings, combined with others, confirm a dual function of ANGPTL2 signaling in cancer pathology and provide novel insight into the regulation of cancer immunity.

\section{Results}

ANGPTL2 expression in tumor versus stromal cells has opposing effects on cancer progression

$\mathrm{Xp} 11.2$ translocation renal cell carcinoma (tRCC) is an early onset subtype of kidney cancer associated with various TFE3 gene fusions, and resultant constitutive expression of TFE3 chimeric proteins and induction of TFE3 targets underlies Xp11.2 tRCC development and progression (Ross and Argani 2010; Ellis et al. 2014; Kauffman et al. 2014). To investigate target genes induced by constitutive activation of TFE3 chimeric proteins in renal tubular epithelial cells, we performed microarray analysis using HK-2/PRCC-TFE3, HK-2/NONO-TFE3, and HK-2/ SFPQ-TFE3 lines, which are human renal tubular epithelial lines harboring three different doxycycline-dependent TFE3 fusion genes (Fig. 1A). Numerous genes were up-regulated doxycycline-treated versus doxycycline-untreated lines, and 165 of those genes were up-regulated in all three lines (Fig. 1A; Supplemental Table S1). Interestingly, we found that ANGPTL2 was up-regulated in all three lines as a gene of commonly up-regulated 165 genes (Fig. 1B). Furthermore, we confirmed that ANGPTL2 protein levels in doxycycline-treated lines were markedly higher than those in untreated lines (Fig. 1C). Because we previously showed that increased tumor-cell-derived ANGPTL2 accelerates tumor progression of human lung and breast cancer cells, and osteosarcoma cells by activating downstream signaling via integrin a $5 \beta 1$ (Endo et al. 2012; Odagiri et al. 2014), we began to investigate whether ANGPTL2 functions in kidney cancer progression.
To investigate roles of ANGPTL2 in development and progression of tRCC, we generated Chd16-Cre/ Rosa ${ }^{\text {LSL-PRCC-TFE3/+ }}$ mice that specifically induce the PRCC-TFE3 fusion gene in renal tubular epithelial cells (Supplemental Fig. S1A; Baba et al. 2019; Kurahashi et al. 2019). Chd16-Cre/Rosa ${ }^{\text {LSL-PRCC-TFE3/+ }}$ mice developed renal cell carcinoma characterized by dilated renal tubules and cyst formation by $40 \mathrm{wk}$ of age, with an incidence of $100 \%$, and their median survival time was 344 d. To evaluate ANGPTL2 function in renal cancer progression, we crossed Chd16-Cre/Rosa ${ }^{\text {LSL-PRCC-TFE3/+ }}$ mice with ANGPTL2 mutant mice (either Angpt12 ${ }^{-/-}$or Angpt12 ${ }^{\mathrm{F} / \mathrm{F}}$ mice) to achieve ANGPTL2 deficiency in either the whole body or specifically in renal tubular epithelial cells, respectively (Fig. 1D; Supplemental Fig. S1A).

Consistent with reported ANGPTL2 tumor-promoting activity, ANGPTL2 deletion specifically in renal tubular epithelial cells slowed tRCC progression, and survival of Chd16-Cre/Rosa ${ }^{\text {LSL-PRCC-TFE } 3 /+} /$ Angptl2 ${ }^{\mathrm{F} / \mathrm{F}}$ mice was significantly prolonged compared with that of Chd16Cre/Rosa $a^{\text {LSL-PRCC-TFE3/+ }}$ mice (Supplemental Fig. S1B). As anticipated, by 40 wk of age, Chd16-Cre/ Rosa $a^{\text {LSL-PRCC-TFE3/+ }}$ mice showed dilated renal tubules, cyst formation, and tumor development with papillary structure, whereas such histological abnormalities were rarely observed in the kidney of Chd16-Cre/ Rosa $^{\text {LSL-PRCC-TFE } 3 /+} /$ Angptl2 ${ }^{\mathrm{F} / \mathrm{F}}$ mice (Fig. 1E,F), results in accord with a role for ANGPTL2 in tumor progression. Unexpectedly, however, survival of Chd16-Cre/ Rosa $^{\text {LSL-PRCC-TFE3/+ }} /$ Angptl2 ${ }^{-/-}$mice was significantly shortened compared with that of Chd16-Cre/ Rosa $^{\text {LSL-PRCC-TFE3/+ }} /$ Angptl2 ${ }^{\mathrm{F} / \mathrm{F}}$ mice (Supplemental Fig. S1B). By 40 wk of age, Chd16-Cre/Rosa ${ }^{\text {LSL-PRCC-TFE } 3 /+} /$ Angpt12 ${ }^{-1-}$ mice exhibited striking renal swelling and exacerbated tRCC pathologies, including dilated renal tubules and tumor development (Fig. 1E,F). In addition, at $40 \mathrm{wk}$ of age, Chd16-Cre/Rosa ${ }^{\text {LSL-PRCC-TFE3/+ }} /$ Angpt12 ${ }^{-/-}$mice exhibited significantly increased levels of serum blood urea nitrogen (BUN), indicating tumor development-associated renal failure (Supplemental Fig. S1C).

We further analyzed expression of TFE3 chimeric protein and ANGPTL2 in kidney tissues from wildtype (WT), Chd16-Cre/Rosa ${ }^{\text {LSL-PRCC-TFE3/+ }}$ Chd16Cre/Rosa ${ }^{\text {LSL-PRCC-TFE3/+ }} /$ Angpt12 ${ }^{\mathrm{F} / \mathrm{F}}$, and Chd16-Cre/ Rosa ${ }^{\text {LSL-PRCC-TFE3/+ }} /$ Angpt12 ${ }^{-/-}$mice at $40 \mathrm{wk}$ of age (Supplemental Fig. S2). Immunohistochemical analysis for TFE3 revealed no TFE3-positive cells in kidney tissues of WT mice (Supplemental Fig. S2A). In contrast, Chd16Cre/Rosa ${ }^{\text {LSL-PRCC-TFE3/+ }}$ Chd16-Cre/Rosa ${ }^{\text {LSL-PRCC-TFE3/+ } /}$ Angpt12 ${ }^{\mathrm{F} / \mathrm{F}}$, and Chd16-Cre/Rosa ${ }^{\text {LSL-PRCC-TFE3/+ }} /$ Angpt12 $^{-/-}$ mice exhibited nuclear accumulation of PRCC-TFE3 chimeric proteins in renal tubular epithelial cells and tumor cells (Supplemental Fig. S2A). Moreover, immunohistochemical analysis for ANGPTL2 in WT mice revealed that podocytes in kidney tissue, but not renal tubular epithelial cells or stromal cells, abundantly expressed ANGPTL2 (Supplemental Fig. S2B). In contrast, we observed increased ANGPTL2 expression in renal tubular epithelial cells, tumor cells, and some stromal cells in kidney tissues from Chd16-Cre/Rosa $a^{\text {LSL-PRCC-TFE3/+ }}$ mice 
A
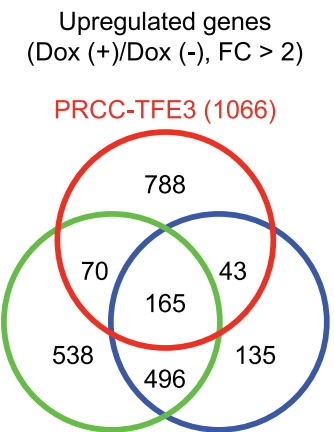

NONO-TFE3 (1269)

SFPQ-TFE3 (839)

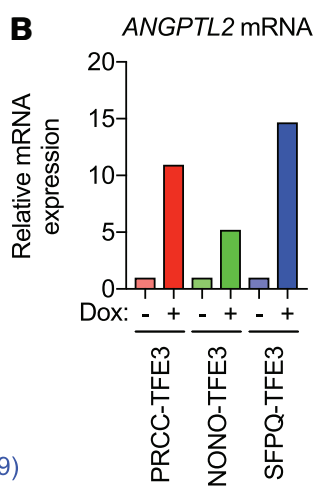

C

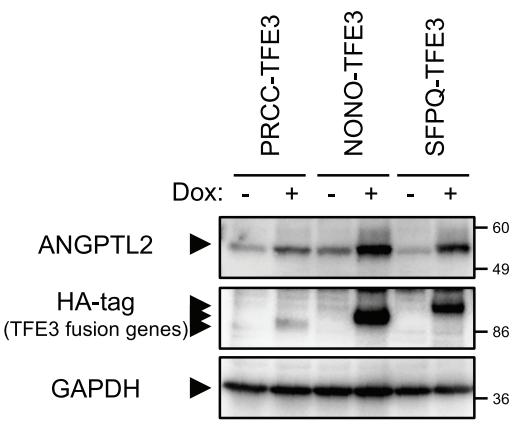

D

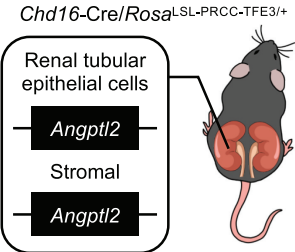

E

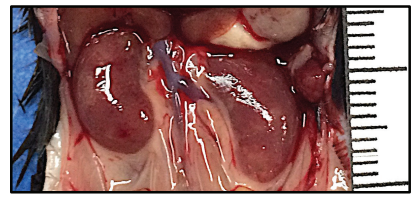

$\mathbf{F}$

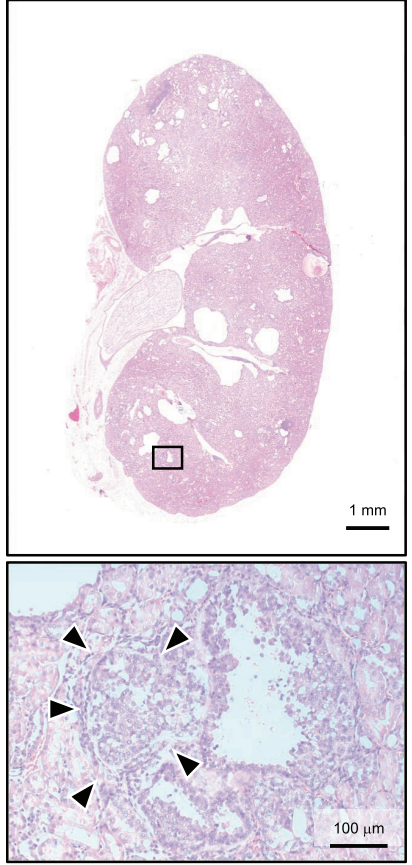

Chd16-Cre/RosaLSL-PRCC-TFE3/+/Angpt/2F/F
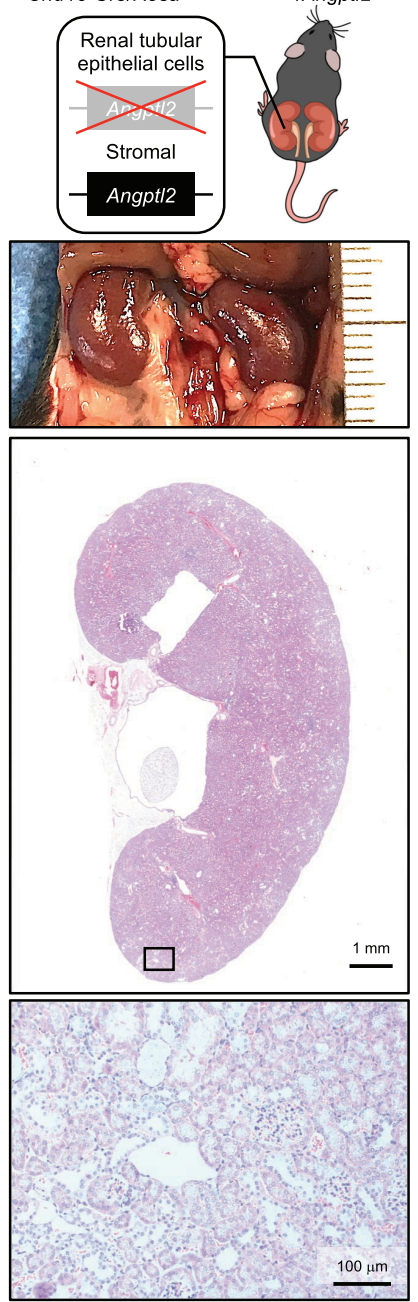

Chd16-Cre/RosaLSL-PRCC-TFE3/+/Angpt/2-/-
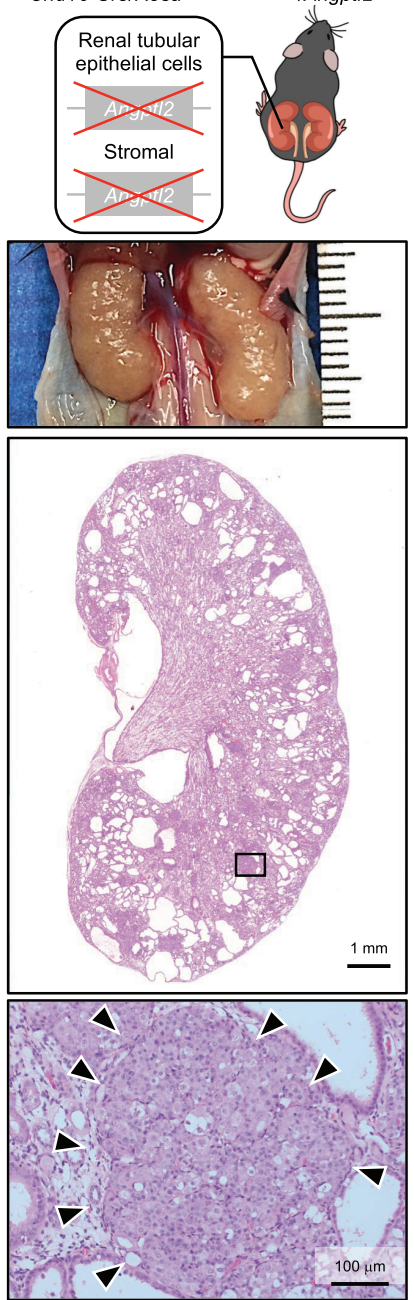

Figure 1. Tumor stroma-derived ANGPTL2 suppresses tumor progression. (A) Gene expression profiling of HK-2/PRCC-TFE3, HK-2/ NonO-TFE3, and HK-2/PSF-TFE3 cells treated with $(+)$ or without $(-)$ doxycycline (Dox) based on microarray analysis. Venn diagram shows number of genes up-regulated approximately twofold in doxycycline-treated versus doxycycline-untreated cells. $(B)$ Comparison of ANGPTL2 mRNA levels between doxycycline-treated and doxycycline-untreated cells based on microarray analysis. Levels in doxycycline-untreated cells were set to 1. (C) Representative immunoblotting of ANGPTL2 and TFE3 chimeric proteins (HA-tag) in HK-2/ PRCC-TFE3, HK-2/NonO-TFE3, and HK-2/PSF-TFE3 cells treated with (+) or without (-) Dox. GAPDH served as a loading control. $(D)$ Schematic representation of the mouse model used. In kidney tissues of Chd16-Cre/Rosa ${ }^{\text {LSL-PRCC-TFE } 3 /+}$ mice, Angpt12 is expressed in both renal tubular epithelial cells and stromal cells. However, in Chd16-Cre/Rosa ${ }^{\text {LSL-PRCC-TFE } 3 /+} /$ Angpt12 ${ }^{\mathrm{F} / \mathrm{F}}$ mice, Angpt12 is specifically deleted in renal tubular epithelial cells. In addition, Chd16-Cre/Rosa ${ }^{\text {LSL-PRCC-TFE3/+ }} /$ Angpt12 ${ }^{-/-}$mice lack Angpt12 in both renal tubular epithelial cells and stromal cells. (E) Gross appearance of kidney of indicated mice at 40 wk of age. $(F)$ Representative H\&E staining images of longitudinal sections of kidney tissues from indicated mice at $40 \mathrm{wk}$ of age. Bottom panel is a magnification of the corresponding square in top panel. Arrowheads indicate a tumor. Scale bar, $1 \mathrm{~mm}($ top $)$ and $100 \mu \mathrm{m}$ (bottom). 
(Supplemental Fig. S2B). However, we did not observe increased ANGPTL2 expression in renal tubular epithelial cells in kidney tissues from Chd16-Cre/Rosa $a^{\text {LSL-PRCC-TFE3/+ }}$ Angpt12 ${ }^{\mathrm{F} / \mathrm{F}}$ mice, nor did we detect ANGPTL2 in kidney tissues from Chd16-Cre/Rosa ${ }^{\text {LSL-PRCC-TFE3/+ }} /$ Angptl2 ${ }^{-/-}$ mice. Taken together, these results suggest that ANGPTL2 deficiency in the host tumor microenvironment accelerates tumor progression. Furthermore, these results support the idea that ANGPTL2 has a dual function in cancer progression and suggest that ANGPTL2 expression in host tumor microenvironment contributes to tumor suppression while ANGPTL2 expression in tumor cells exacerbates tumor progression.

\section{ANGPTL2 deficiency in host tumor microenvironmental cells enhances tumor growth}

To assess ANGPTL2 function in the host tumor microenvironment, we used a murine syngeneic cancer model extensively used to evaluate reciprocal interactions between cancer cells and the tumor microenvironment, including host anti-tumor immune responses. Specifically, we chose a B16-OVA melanoma model, in particular because B16-OVA tumor cells do not express ANGPTL2 (Supplemental Fig. S3A,B), and use of this system can readily distinguish ANGPTL2 function in the microenvironment from that in a tumor cell. B16-OVA melanoma cells do express a non-secreted form of chicken ovalbumin (OVA) as a surrogate tumor antigen, which can be conveniently used to follow immune responses directed against this antigen. To establish the model, we injected B16-OVA cells into the back flanks of WT or Angpt12 ${ }^{-/-}$mice and monitored tumor volume. Angpt12 ${ }^{-1-}$ mice showed an increase in volume and weight of subcutaneously grafted B16-OVA cells relative to WT mice (Fig. 2A-C). Moreover, survival of Angpt12-/- mice bearing B16-OVA tumors was significantly shortened compared with that of WT tumorbearing mice (Fig. 2D), suggesting a tumor suppressive for ANGPTL2 in this system.

\section{PDGFR $\alpha^{+}$fibroblasts produce ANGPTL2 to inhibit tumor growth}

We next searched for the in vivo source of ANGPTL2 in the tumor microenvironment. Immunohistochemical analysis of B16-OVA tumors grown in WT mice revealed that stromal cells, but not tumor cells, expressed ANGPTL2 proteins (Supplemental Fig. S3C). ANGPTL2 signals partially colocalized with ER-TR $7^{+}$fibroblasts, but not with $\mathrm{CD} 45^{+}$leukocytes, $\mathrm{CD} 68^{+}$macrophages, or $\mathrm{CD} 1^{+}$endothelial cells (Fig. 3A). We also examined Angpt12 mRNA expression in various stromal cells isolated from B16-OVA tumors and confirmed that cancerassociated fibroblasts (CAFs) abundantly express Angpt12 mRNA, as compared with $\mathrm{CD} 45^{+}$leukocytes and CD $31^{+}$ endothelial cells (Supplemental Fig. S3D). Platelet-derived growth factor receptor a (PDGFRa) and PDGFR $\beta$ are markers of CAFs (Koliaraki et al. 2017; Bu et al.
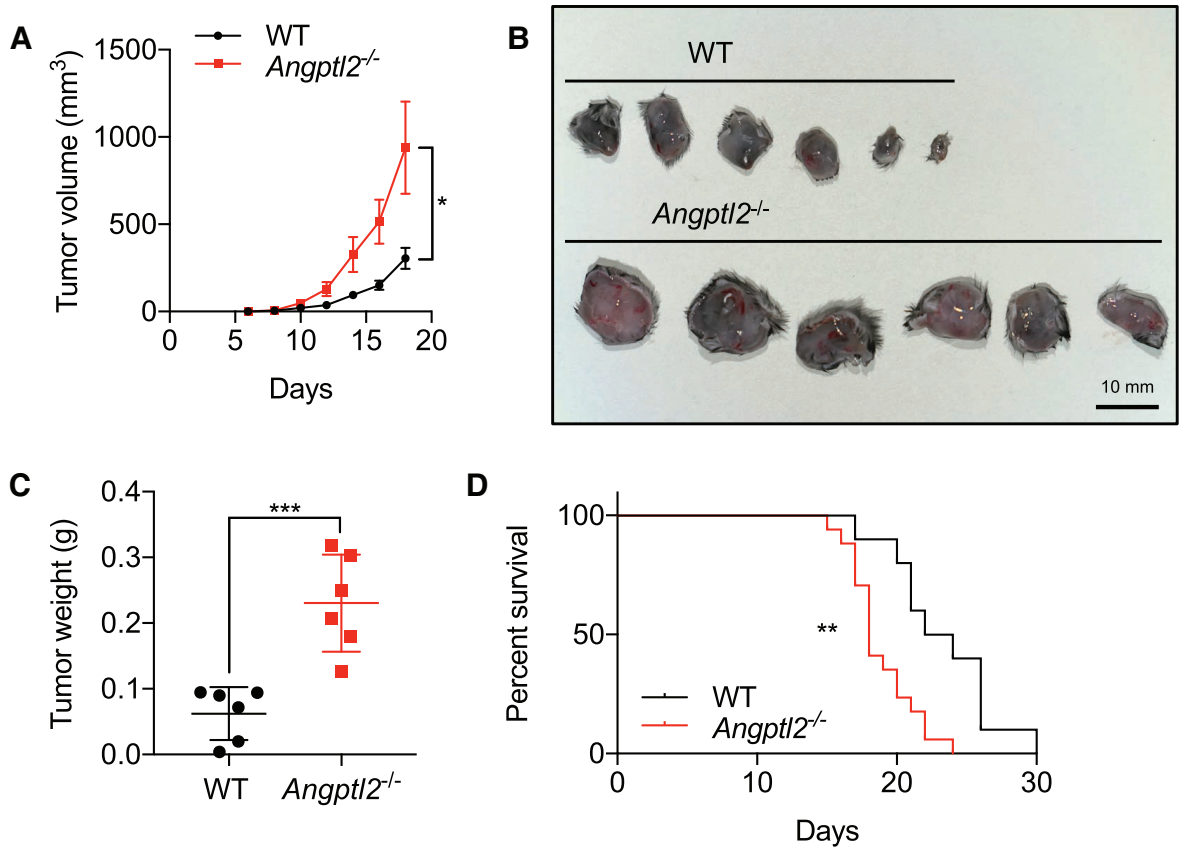

Figure 2. Host ANGPTL2 deficiency enhances tumor growth. $(A)$ Comparison of tumor volumes in female WT and Angpt12-/- mice bearing B16-OVA cells. Data are means \pm SEM; $n=8$ tumors per group. $\left(^{*}\right) P<0.05$, two-way ANOVA test. $(B, C)$ Gross appearance $(B)$ of tumors extirpated from WT and Angpt $12^{-/-}$mice $14 \mathrm{~d}$ after implantation and tumor weight $(C)$. Data are means $\pm S D ; n=6$ tumors per group. $\left(^{* * *}\right) P<0.001$, unpaired $t$-test. Scale bar, $10 \mathrm{~mm}$. $(D)$ Kaplan-Meier tumor-free survival curves of WT and Angpt $12^{-/-}$mice bearing B16-OVA tumors ( $n=10$ per WT group, $n=17$ mice per Angptl2 ${ }^{-/-}$group). Results are pooled from two independent experiments. $\left.{ }^{* *}\right) P<$ $0.01, \log$-rank test. 


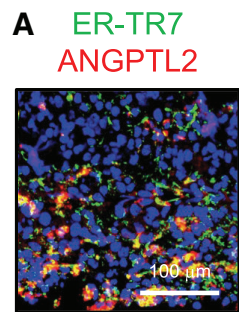

ANGPTL2

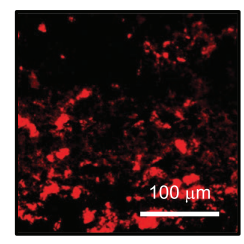

ER-TR7

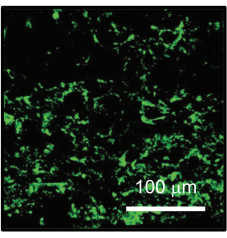

C
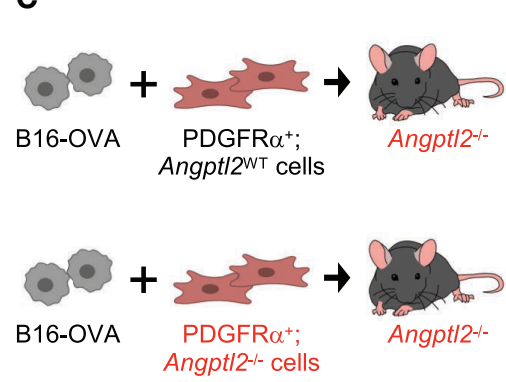

CD31

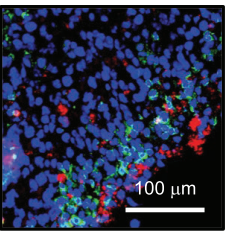

ANGPTL2

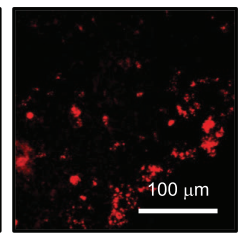

CD45
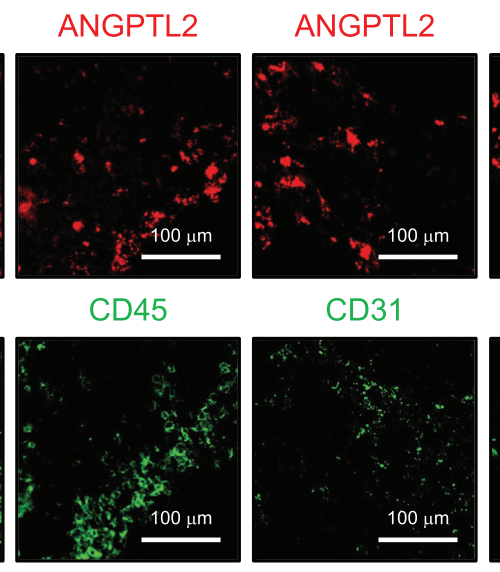
ANGPTL2

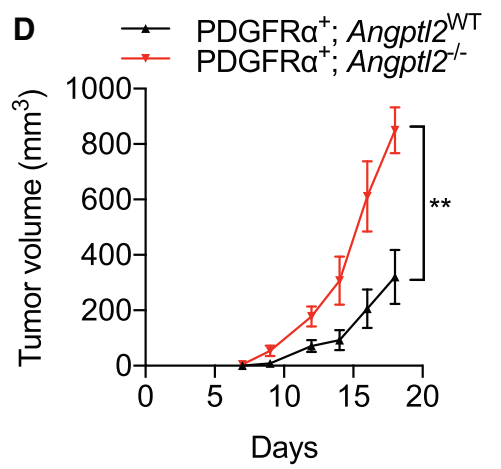

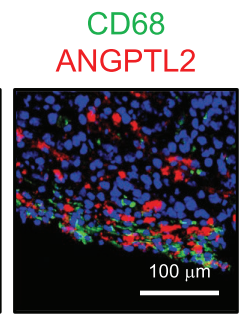

ANGPTL2

B

PDGFR $\alpha$
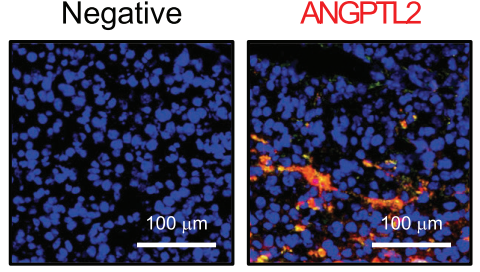

ANGPTL2

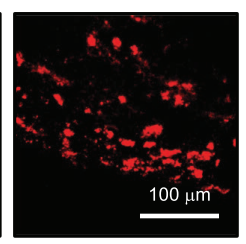

CD68
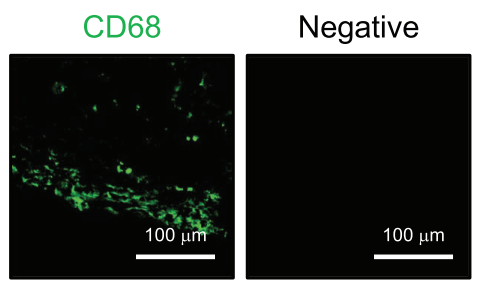

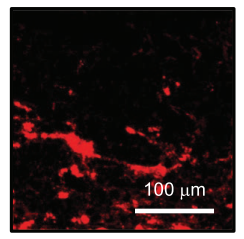

PDGFR $\alpha$

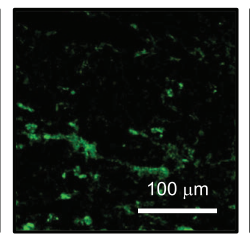

E
E

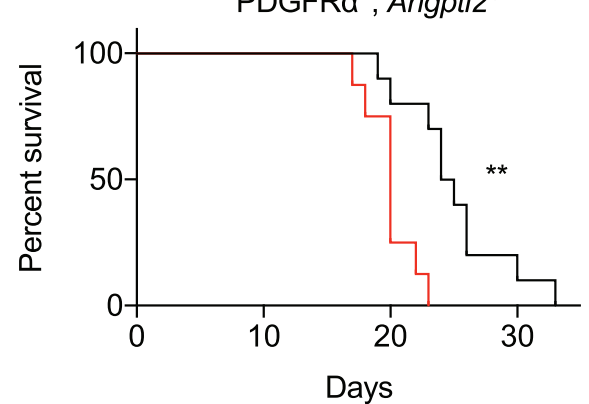

Figure 3. PDGFRa ${ }^{+}$fibroblast-derived ANGPTL2 inhibits tumor growth. $(A, B)$ Immunofluorescent staining for ANGPTL2 (red) and indicated marker proteins (green) in tumor tissues of WT mice bearing B16-OVA tumors, $14 \mathrm{~d}$ after implantation. Nuclei are counterstained with DAPI (blue). Scale bar, $100 \mu \mathrm{m}$. (C) Schematic illustrating the experimental design of coinjection of B16-OVA cells and PDGFRa ${ }^{+}$

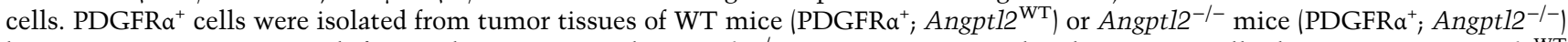
bearing B16-OVA tumors $21 \mathrm{~d}$ after implantation. Female Angpt12-/- mice were coinjected with B16-OVA cells plus PDGFRa ${ }^{+}$; Angpt12 ${ }^{\mathrm{WT}}$ or PDGFRa ${ }^{+}$; Angpt12 ${ }^{-/}$cells. (D) Comparison of tumor volumes in Angpt12-/- mice coinjected with B16-OVA cells plus PDGFRa ${ }^{+}$; Angpt12 ${ }^{\mathrm{WT}}$ or PDGFRa ${ }^{+}$; Angpt12 ${ }^{-/}$cells. Data are means $\pm \mathrm{SEM}_{;} n=6$ tumors per group. $\left(^{* *}\right) P<0.01$, two-way ANOVA test. (E) Kaplan-Meier tumor-free survival curves of Angplt2 $2^{-1-}$ mice coinjected with B16-OVA cells plus PDGFRa ${ }^{+}$; Angpt12 ${ }^{\text {WT }}$ or PDGFRa ${ }^{+}$; Angpt12 ${ }^{-/-}$cells ( $n=10$ mice for PDGFRa ${ }^{+}$; Angpt $12^{\mathrm{WT}}$ group, $n=8$ mice for PDGFRa ${ }^{+}$; Angpt $12^{-/-}$group). Results are pooled from two independent experiments. $\left(^{* *}\right) P<0.01, \log$-rank test.

2019). PDGFRa ${ }^{+}$CAFs and PDGFR $\beta^{+}$CAFs reportedly originate from tissue-resident fibroblasts and pericytes, respectively, and play tumor-promoting roles in various cancers (Sugimoto et al. 2006; Roswall and Pietras 2012; Ha et al. 2014; Koliaraki et al. 2017; Bu et al. 2019). Interestingly, we found that ANGPTL2 was predominantly expressed in PDGFR ${ }^{+}$but not PDGFR $\beta^{+}$fibroblasts (Fig. 3B). Moreover, expression levels of Angptl2 mRNA in PDGFRa $^{+}$CAFs were higher than those in PDGFRa ${ }^{-}$ CAFs (Supplemental Fig. S3D). We also asked whether PDGFRa ${ }^{+}$fibroblasts were an in vivo source of ANGPTL2 in tRCC lesions. Immunohistochemical analysis of kid- ney tissues of Chd16-Cre/Rosa $a^{\text {LSL-PRCC-TFE3/+ }}$ mice at 40 wk of age revealed that ANGPTL2 is expressed by PDGFRa ${ }^{+}$fibroblasts (Supplemental Fig. S3E). These results suggest that $\mathrm{PDGFRa}^{+}$fibroblasts are the in vivo source of ANGPTL2.

We asked whether ANGPTL2 produced by PDGFRa ${ }^{+}$fibroblasts can suppress tumor growth. To do so, we subcutaneously injected Angpt12-/- mice with B16-OVA cells together with PDGFR $\alpha^{+}$cells isolated from tumor tissues of either WT mice (PDGFRa ${ }^{+}$; Angptl2 ${ }^{\mathrm{WT}}$ ) or Angpt12 ${ }^{-/-}$ mice (PDGFRa ${ }^{+}$; Angptl2 $2^{-l}$ ) bearing B16-OVA tumors (Fig. 3C). Angpt12 ${ }^{-/-}$mice implanted with PDGFRa ${ }^{+}$; 
Angpt12 ${ }^{\mathrm{WT}}$ cells showed a substantial decrease in tumor growth relative to Angptl2 $2^{-/}$mice implanted with PDGFRa $^{+}$; Angpt12-/- cells (Fig. 3D). Survival of mice implanted with PDGFRa ${ }^{+}$; Angpt12 ${ }^{\mathrm{WT}}$ cells was also significantly prolonged relative to that of mice implanted with PDGFRa $^{+}$; Angptl2 $2^{-/-}$cells (Fig. 3E). Collectively, this data suggests that PDGFRa ${ }^{+}$fibroblast-derived ANGPTL2 in the tumor microenvironment has tumor-suppressive function.

ANGPTL2 expression in host tumor microenvironmental cells is required to promote anti-tumor immune responses

We next addressed the potential mechanisms of tumor suppression by ANGPTL2 in this context. Therefore, we performed histopathology of tumors from WT and Angpt12 ${ }^{-/-}$mice. We observed decreased numbers of tumor-infiltrating immune cells in Angptl2 ${ }^{-/-}$versus WT mice (Fig. 4A), a finding confirmed by staining with the pan-leukocyte marker CD45 (Fig. 4B,C). These suggest that decreased tumor-infiltrating immune cells may be associated with enhanced tumor growth in Angpt12-/mice. Given that the cellular immunity, particularly $\mathrm{CD}^{+} \mathrm{T}$ cells, plays a central role in mediating robust anti-tumor immune responses (Gajewski et al. 2013), we used flow cytometry to evaluate tumor infiltration by $\mathrm{CD}^{+} \mathrm{T}$ cells in Angptl2 ${ }^{-/-}$and WT mice and observed a significant decrease in the number of tumor-infiltrating $\mathrm{CD}^{+} \mathrm{T}$ cells in Angptl2 ${ }^{-/-}$relative to WT mice (Fig. 4D). We also observed less T-cell cross-priming in CD8 ${ }^{+}$ $\mathrm{T}$ cells isolated from tumor-draining lymph nodes of Angpt12 ${ }^{-1-}$ mice based on staining for MHC (major histocompatibility complex) class I OVA tetramers $\left(\mathrm{H}-2 \mathrm{~K}^{\mathrm{b}}\right.$; $\mathrm{OVA}_{257-264}$ ) (Fig. 4E; Supplemental Fig. S4A). Moreover, $\mathrm{CD}^{+} \mathrm{T}$ cells isolated from tumor-draining lymph nodes of Angpt12-/- mice produced lower levels of the effector cytokine granzyme B $(\mathrm{GzmB})$ than did comparable cells from WT mice upon ex vivo stimulation with $\mathrm{OVA}_{257-264}$ (SIINFEKL) peptide (an $\mathrm{H}-2 \mathrm{~K}^{\mathrm{b}}$-restricted
A

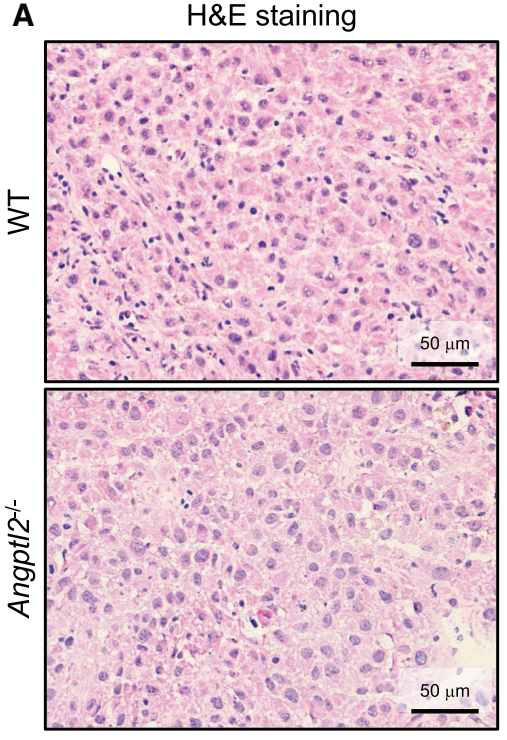

B
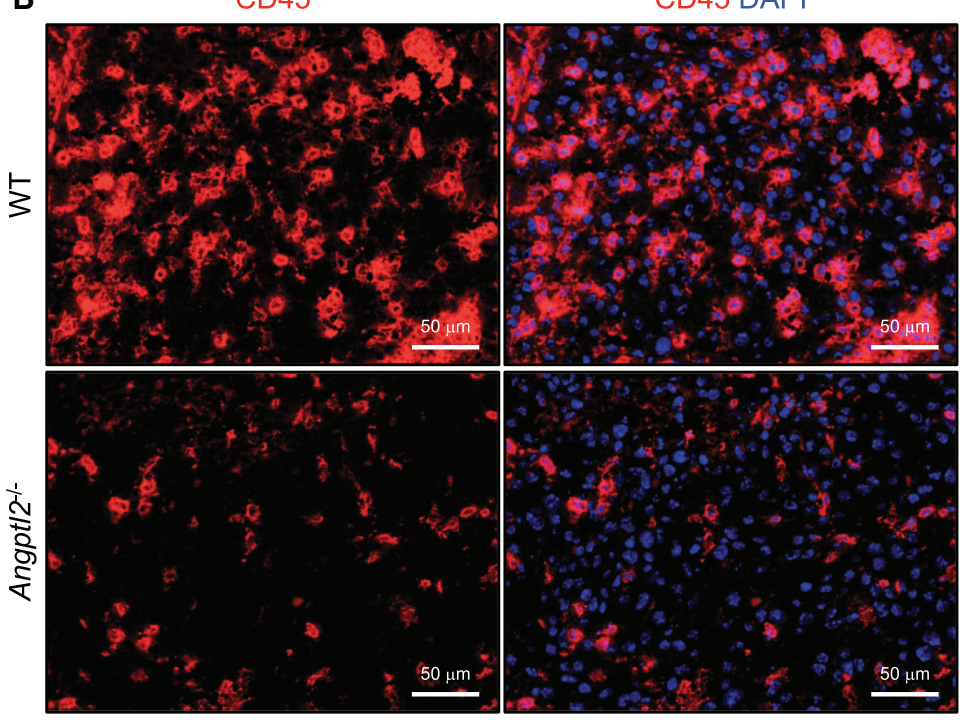

C

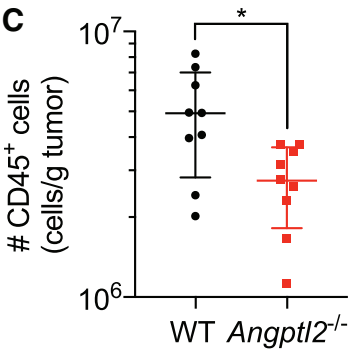

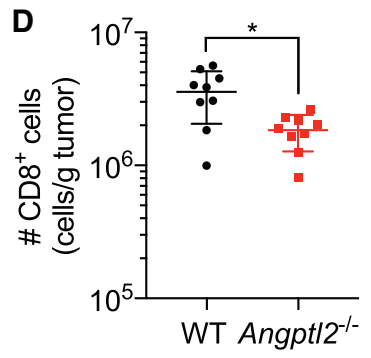
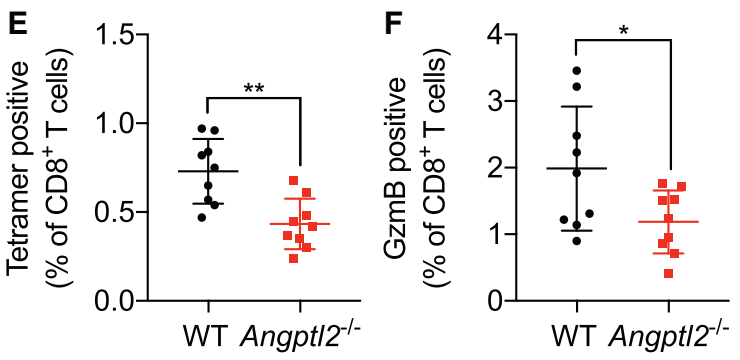

Figure 4. Host ANGPTL2 deficiency decreases anti-tumor immune responses. $(A)$ Representative H\&E-stained images of tumor tissues from WT or Angpt12 ${ }^{-/}$mice bearing B16-OVA tumors, $14 \mathrm{~d}$ after implantation. Scale bar, $50 \mu \mathrm{m}$. (B) Immunofluorescent staining for CD45 (red) in tumor tissues from WT or Angpt12-/- mice bearing B16-OVA tumors, $14 \mathrm{~d}$ after implantation. Nuclei are counterstained with DAPI (blue). Scale bar, $50 \mu \mathrm{m}$. $(C, D)$ The absolute number of $\mathrm{CD}^{2} 5^{+}$cells $(C)$ and $C D 8^{+} \mathrm{T}$ cells $(D)$ infiltrating into the tumor tissues of WT and Angpt12 ${ }^{-1-}$ mice bearing B16-OVA tumors at $14 \mathrm{~d}$ after implantation, assessed by FACS analysis. Data are means \pm SD, pooled from three independent experiments; $n=9$ tumors for each group. $\left({ }^{*}\right) P<0.05$, Mann-Whitney test. $(E, F)$ Frequency of MHC class I OVA tetramer ${ }^{+} \mathrm{CD}^{+} \mathrm{T}$ cells $(E)$ and $\mathrm{CD} 8^{+} \mathrm{T}$ cells expressing Granzyme $\mathrm{B}(\mathrm{GzmB})(F)$ in inguinal lymph nodes of WT or Angpt12 ${ }^{-/-}$mice bearing B16-OVA tumors, $14 \mathrm{~d}$ after implantation, as assessed by FACS analysis. Frequency of both is shown as a percentage of total CD ${ }^{+} \mathrm{T}$ cells. Data are means $\pm \mathrm{SD}$, pooled from three independent experiments; $n=9$ mice per group. $\left(^{* *}\right) P<0.01,\left(^{*}\right) P<0.05$, unpaired $t$-test. 
OVA class I epitope) (Fig. 4F; Supplemental Fig. S4B). These observations suggest that PDGFRa ${ }^{+}$fibroblast-derived ANGPTL2 enhances tumor-specific cellular immune responses.

To further confirm an association between ANGPTL2 and anti-tumor immune responses, we asked whether ANGPTL2 deficiency diminishes anti-tumor immune responses in tRCC model mice. We observed a moderate number of $\mathrm{CD} 45^{+}$leukocytes in tRCC tumor lesions from Chd16-Cre/Rosa ${ }^{\text {LSL-PRCC-TFE3/+ }}$ mice (Supplemental Fig. S5A-C). On the other hand, Chd16-Cre/ Rosa ${ }^{\text {LSL-PRCC-TFE3/+ }} /$ Angptl2 ${ }^{-/-}$mice showed fewer tumor-infiltrating $\mathrm{CD} 45^{+}$leukocytes compared with Chd16-Cre/Rosa ${ }^{\text {LSL-PRCC-TFE } 3 /+}$ mice (Supplemental Fig. S5A-C). Furthermore, the number of tumor-infiltrating $\mathrm{CD}^{+} \mathrm{T}$ cells in kidney tissue from Chd16-Cre/ Rosa ${ }^{\text {LSL-PRCC-TFE3/+ }} /$ Angptl2 ${ }^{-/-}$mice significantly decreased compared with numbers seen in Chd16-Cre/ Rosa ${ }^{\text {LSL-PRCC-TFE3/+ }}$ mice (Supplemental Fig. S5D). These results suggest that ANGPTL2 expression in host tumor microenvironmental cells is required to promote anti-tumor immune responses not only in a B16-OVA syngeneic mouse model, but also in a tRCC mouse model.

\section{ANGPTL2 activates dendritic cells to promote CD8 T cell cross-priming}

Although numerous mechanisms regulate anti-tumor immune responses, given that we observed attenuated $\mathrm{CD}^{+}$ $\mathrm{T}$ cell cross-priming in Angpt12 ${ }^{-/-}$mice (Fig. 4E; Supplemental Fig. S4A), we hypothesized that ANGPTL2 stimulates cross-presentation by antigen-presenting cells. To test this, we assayed the effects of ANGPTL2 on MHC class I-restricted cross-presentation using bone-marrowderived dendritic cells (BMDCs) as antigen-presenting cells. Antigen cross-priming of OVA was monitored using the $\mathrm{CD}^{+} \mathrm{T}$ cell hybridoma B3Z expressing OVA-specific T-cell-receptor, which carry $\beta$-galactosidase construct controlled by the interleukin-2 (IL-2) promoter (Karttunen et al. 1992). We found that lipopolysaccharide (LPS)-activated WT or Angpt12-/- BMDCs similarly promoted antigen cross-presentation (Fig. 5A) and showed comparable production of the effector cytokine IL-12 following LPS stimulation (Fig. 5B). Moreover, qRT-PCR analysis revealed that WT BMDCs expressed minimal levels of Angpt12 mRNA (Supplemental Fig. S6A), suggesting that ANGPTL2 released from PDGFRa ${ }^{+}$fibroblast activates dendritic cells to enhance antigen cross-presentation. To assess this mechanism, we prestimulated WT BMDCs with recombinant ANGPTL2 protein (rANGPTL2) and conducted an in vitro cross-presentation assay. Pre-treatment of WT BMDCs with rANGPTL2 significantly augmented antigen cross-presentation relative to untreated BMDCs (Fig. 5C). rANGPTL2-pretreated BMDCs showed increased IL-12 production (Fig. 5D; Supplemental Fig. S6B), MHC class II expression (Fig. 5E; Supplemental Fig. S6C), and expression of costimulatory molecules (CD86, CD80, and CD40) (Fig. 5F; Supplemental Fig. $\mathrm{S} 6 \mathrm{D})$, indicative of BMDC activation. Overall, these results suggest that exogenous ANGPTL2 activates den- dritic cells and enhances antigen cross-presentation to facilitate $\mathrm{CD}^{+} \mathrm{T}$ cell cross-priming.

To evaluate whether ANGPTL2-activated dendritic cells inhibit tumor progression in vivo, we performed an adoptive transfer experiment in which mice implanted with B16-OVA cells are subcutaneously injected with SIINFEKL peptide-pulsed BMDCs, pretreated with or without rANGPTL2 (Fig. 5G). Adoptive transfer of BMDCs pulsed with or without SIINFEKL peptide had no significant anti-tumor effects compared with PBS group (Fig. 5H,I). However, mice transferred with rANGPTL2-pretreated BMDCs pulsed with SIINFEKL peptide showed decreased tumor volume and significantly prolonged survival relative to $\mathrm{PBS}$ group (Fig. 5H,I), suggesting that ANGPTL2-activated dendritic cells might be capable of inducing an anti-tumor immune response.

\section{ANGPTL2 activates dendritic cells via PIR-B-NOTCH signaling}

We next investigated molecular mechanisms underlying dendritic cell activation by ANGPTL2. We previously demonstrated that ANGPTL2 signals through integrin a5 $\beta 1$ in endothelial cells (Tabata et al. 2009), cancer cells (Odagiri et al. 2014), and macrophages (Yugami et al. 2016). Flow-cytometry analysis revealed that $\mathrm{CD} 11 \mathrm{c}^{+} \mathrm{MHC} \mathrm{II}^{\mathrm{lo}}$ immature BMDCs express various types of integrins, including $\alpha 5$ and $\beta 1$ (Supplemental Fig. S7A). To determine whether ANGPTL2 activates dendritic cells via integrin $\alpha 5 \beta 1$, we treated BMDCs with anti-integrin $\alpha 5$ or anti-integrin $\beta 1$ blocking antibody to inhibit integrin signaling; however, neither treatment inhibited BMDC activation by ANGPTL2 relative to cells treated with control Ig (Fig. 6A), suggesting that integrin $\alpha 5 \beta 1$ does not mediate ANGPTL2 signaling in dendritic cells. A recent study demonstrated that murine-paired immunoglobulin-like receptor-B [PIR-B; also known as LILRB2 (leukocyte immunoglobulin-like receptor B2) in human] mediates ANGPTL2 signaling in hematopoietic stem cells (Zheng et al. 2012), and PIR-B is expressed on myeloid cells, including dendritic cells (Colonna et al. 2000; Brown et al. 2004). First, we confirmed PIR-B expression in $\mathrm{CD} 11 \mathrm{c}^{+} \mathrm{MHC} \mathrm{II}^{\mathrm{lo}}$ immature BMDCs (Supplemental Fig. S7B). We then found that unlike PIR-B-expressing BMDCs, BMDCs engineered to lack PIR-B expression did not show increases in IL-12 production (Fig. 6B), MHC class II expression (Fig. 6C), or costimulatory molecule expression (Fig. 6D) when treated with rANGPTL2, suggesting that PIR-B is required for ANGPTL2-dependent activation of dendritic cells in this context.

The ANGPTL2-PIR-B axis reportedly activates NOTCH signaling in hematopoietic stem cells (Lin et al. 2015). Furthermore, NOTCH signaling facilitates dendritic cell maturation (Lewis et al. 2011; Guilliams and Scott 2018; Kirkling et al. 2018). Therefore, we hypothesized that ANGPTL2 may stimulate dendritic cells via PIR-B-NOTCH pathway. Indeed, immunoblot analysis showed that treatment of BMDCs with rANGPTL2 increased abundance of both full-length and cleaved forms of NOTCH2 protein, leading to activation of the $\mathrm{NOTCH}$ 

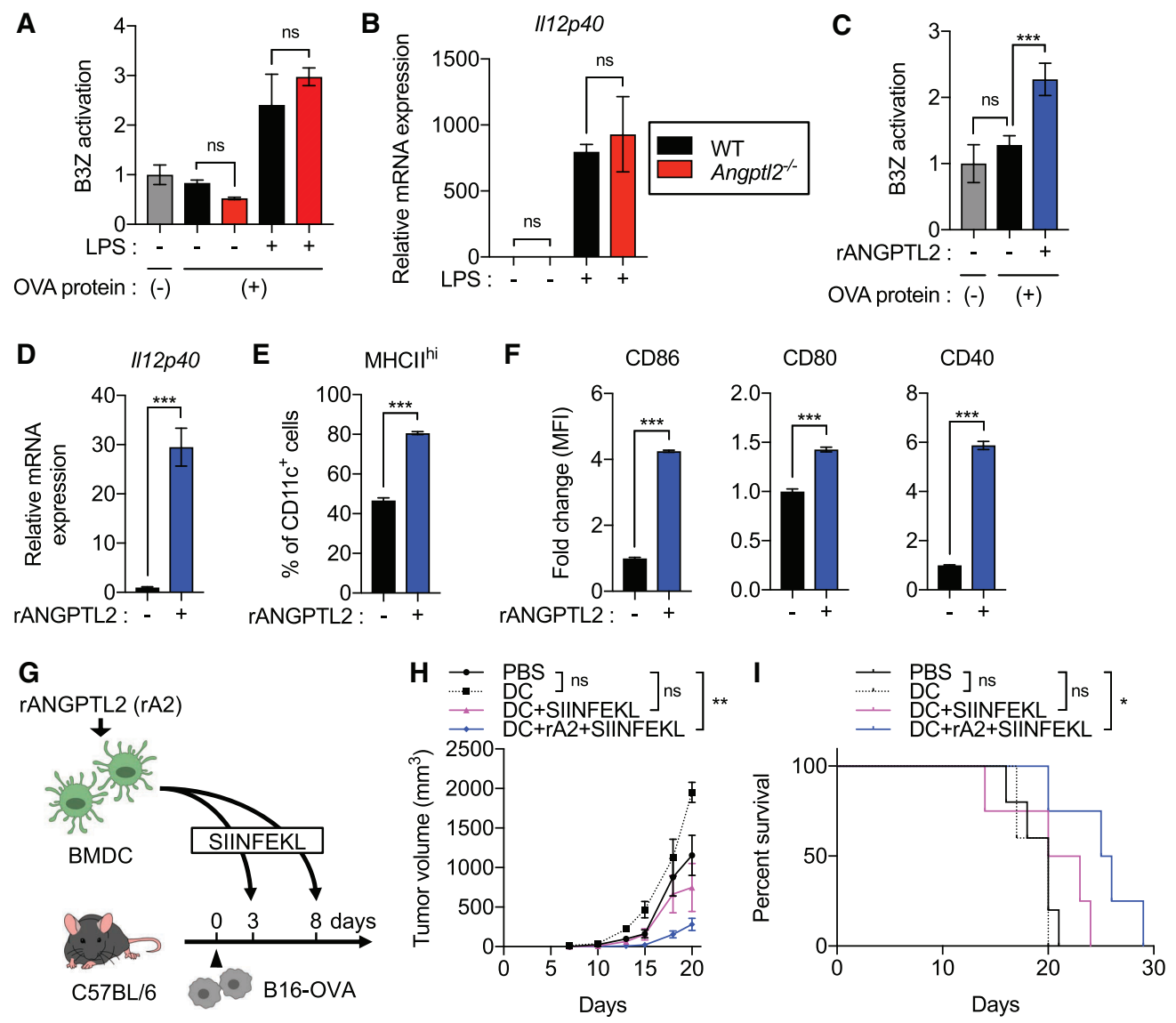

Figure 5. ANGPTL2 stimulates dendritic cell-mediated immune responses. (A) In vitro cross-presentation of OVA proteins by LPS-stimulated or LPS-unstimulated bone-marrow-derived dendritic cells (BMDCs) derived from WT or Angptl2 ${ }^{-/}$mice using the CD8 ${ }^{+}$T-cell hybridoma B3Z. $\beta$-galactosidase activity in B3Z cells incubated with unstimulated BMDCs untreated with OVA proteins was set at 1. Data are means $\pm \mathrm{SD} ; n=4$ per group. (ns) Not significant $(P>0.05)$, one-way ANOVA test followed by Tukey's multiple comparison test. (B) Comparison of levels of $I 112 p 40$ transcripts in LPS-stimulated or LPS-unstimulated BMDCs derived from WT or Angpt12 ${ }^{-/-}$ mice. Levels in unstimulated WT BMDCs were set to 1 . Data are means $\pm \mathrm{SD} ; n=3$ per group. (ns) Not significant $(P>0.05)$, one-way ANOVA test followed by Tukey's multiple comparison test. $(C)$ In vitro cross-presentation of OVA proteins by WT BMDCs stimulated with or without recombinant ANGPTL2 (rANGPTL2) protein using B3Z cells. $\beta$-galactosidase activity in B3Z cells incubated with unstimulated BMDCs untreated with OVA proteins was set to 1 . Data are means \pm SD; $n=4$ per group. $($ ns $)$ Not significant $(P>0.05) ;\left({ }^{* * *}\right) P<$ 0.001, one-way ANOVA test followed by Tukey's multiple comparison test. (D) Comparison of levels of $I 112 p 40$ transcripts in WT BMDCs treated with or without rANGPTL2. Levels in ANGPTL2-untreated BMDCs were set to 1 . Data are means $\pm \mathrm{SD} ; n=3$ per group. $\left({ }^{* * *}\right) P<$ 0.001 , unpaired $t$-test. $(E)$ Frequency of CD11 $\mathrm{c}^{+}$MHC class II (MHC II $)^{\text {hi }}$ cells in WT BMDCs treated with or without rANGPTL2, as assessed by FACS analysis. Frequency is calculated as a percentage of total CD $11 \mathrm{c}^{+}$cells. Data are means $\pm \operatorname{SD} ; n=3$ per group. $\left.{ }^{* * *}\right) P<0.001$, unpaired $t$-test. $(F)$ Relative expression levels (median fluorescence intensity, MFI) of costimulatory molecules (CD86, CD80, and CD40) in WT BMDCs treated with or without rANGPTL2, as assessed by FACS analysis. Levels in ANGPTL2-untreated BMDCs were set to 1. Data are means \pm SD; $n=3$ per group. $\left(^{* * *}\right) P<0.001$, unpaired $t$-test. $(G)$ Schematic illustrating the experimental design of dendritic cell immunization of WT male mice. rA2, recombinant ANGPTL2 protein; SINFEKL, H-2K ${ }^{\mathrm{b}}$-restricted OVA class I epitope. (H) Comparison of tumor volumes in C57BL/6 male mice bearing B16-OVA cells transferred with untreated dendritic cells (DC) or ANGPTL2-treated $(\mathrm{DC}+\mathrm{rA} 2+\mathrm{SIINFEKL})$ or untreated (DC + SIINFEKL) DCs pulsed with SIINFEKL. Data are means \pm SEM; $n=6$ tumors per group. (ns) Not significant $\left.(P>0.05) ;{ }^{* *}\right) P<0.01$, two-way ANOVA test comparing each group with the PBS group. $(I)$ Kaplan-Meier tumor-free survival curves of mice bearing B16-OVA cells transferred with untreated dendritic cells (DC) or ANGPTL2-treated (DC + rA2 + SIINFEKL) or untreated (DC + SIINFEKL) DCs pulsed with SIINFEKL $(n=5$ mice for PBS and DC groups or $n=4$ mice for DC + SIINFEKL and DC $+r A 2+$ SIINFEKL groups). (ns) Not significant $(P>0.05) ;\left(^{*}\right) P<0.05$, log-rank test comparing each group with the PBS group.

pathway, as evidenced by elevated expression of the NOTCH target gene Hes1 (Fig. 6E; Supplemental Fig. S8A). Furthermore, ANGPTL2-induced up-regulation of Hes1 was not observed in Pirb ${ }^{-1-}$ BMDCs (Supplemental Fig. S8A). Importantly, blocking NOTCH signaling by treating BMDCs with the $\gamma$-secretase inhibitor DAPT
(N-[N-(3, 5-difluorophenacetyl-L-alanyl)]-S-phenylglycine t-butyl ester) significantly attenuated ANGPTL2-induced dendritic cell activation and maturation compared with untreated BMDCs, based on decreased IL-12 production (Fig. 6F), MHC class II expression (Fig. 6G), and expression of costimulatory molecules (Fig. $6 \mathrm{H}$ ). These findings 
A

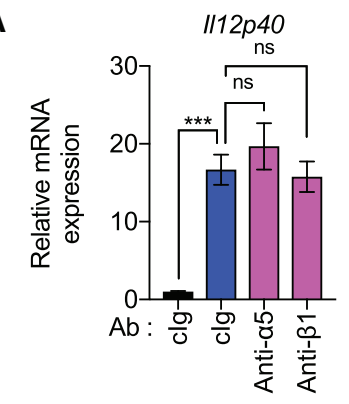

B

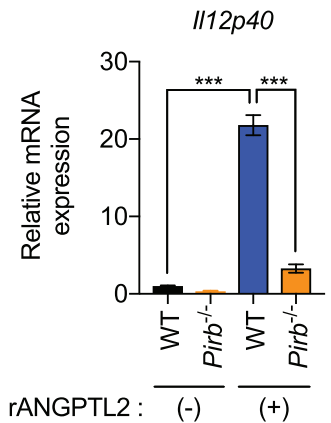

C

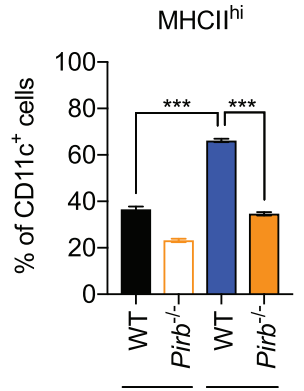

rANGPTL2: $(-) \quad(+)$

CD80

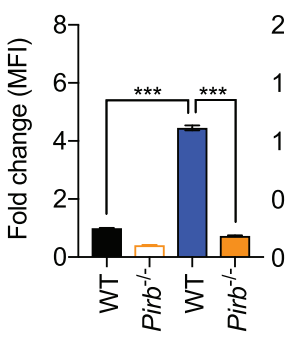

rANGPTL2 : $\overline{(-)} \overline{(+)}$

F

$1 / 12 p 40$

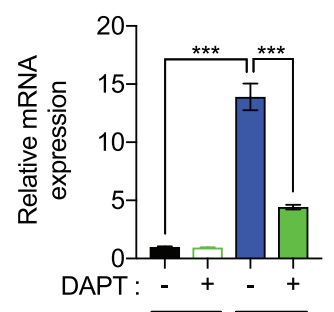

rANGPTL2: $\overline{(-)} \overline{(+)}$

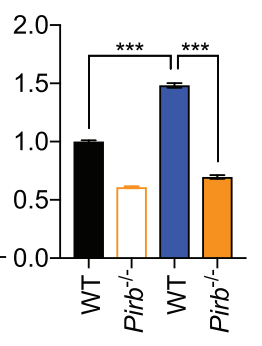

$(-) \overline{(+)}$

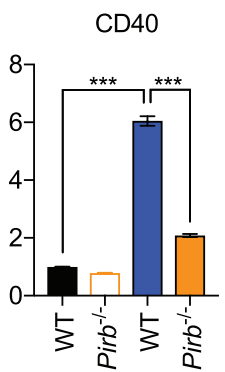

$(-)$
G

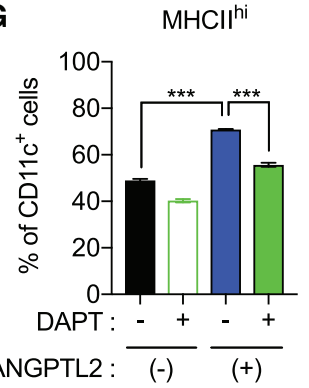

H

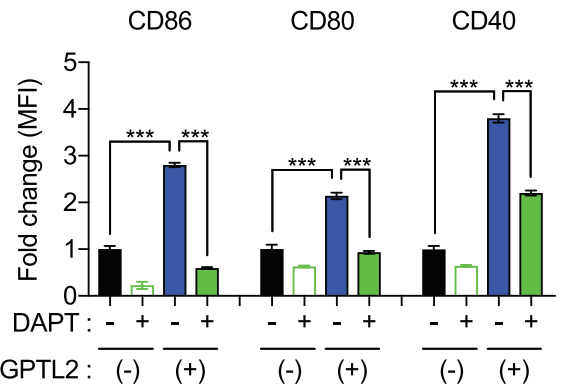

Figure 6. ANGPTL2 activates dendritic cells via PIR-B-NOTCH signaling. (A) Comparison of $I 112 p 40$ transcript levels in ANGPTL2stimulated WT BMDCs pretreated with control Ig (cIG) or anti-integrin antibodies. Levels in ANGPTL2-untreated WT BMDCs were set to 1 . Data are means $\pm \mathrm{SD} ; n=3$ per group. (ns) Not significant $(P>0.05)$, one-way ANOVA test followed by Tukey's multiple comparison test. $(B)$ Comparison of $1112 p 40$ transcript levels in ANGPTL2-treated or ANGPTL2-untreated BMDCs derived from WT or Pirb ${ }^{-1-}$ mice. Levels in ANGPTL2-untreated WT BMDCs were set at 1 . Data are means \pm SD; $n=3$ per group. ( $\left.^{* *}\right) P<0.001$, one-way ANOVA test followed by Tukey's multiple comparison test. $(C, D)$ Frequency of CD11 ${ }^{+} \mathrm{MHC} \mathrm{II}^{\mathrm{hi}}$ cells $(C)$ and relative expression levels $(\mathrm{MFI})$ of costimulatory molecules $(D)$ in ANGPTL2-treated or -untreated BMDCs derived from WT or Pirb ${ }^{-1-}$ mice, as assessed by FACS analysis. Frequency is reported as a percentage of total CD11 $\mathrm{c}^{+}$cells. Expression levels of costimulatory molecules in ANGPTL2-untreated WT BMDCs were set at 1 . Data are means $\pm \mathrm{SD} n=3$ per group. $\left(^{* * *}\right) P<0.001$, one-way ANOVA test followed by Tukey's multiple comparison test. (E) Representative immunoblotting of NOTCH2 in ANGPTL2-treated WT BMDCs. HSC70 served as a loading control. $(F)$ Comparison of levels of $I 112 p 40$ mRNA in ANGPTL2-stimulated WT BMDCs pretreated with or without the NOTCH inhibitor DAPT. Expression levels in WT BMDCs untreated with both ANGPTL2 and DAPT were set to 1 . Data are means $\pm \mathrm{SD} n=3$ per group. $\left.{ }^{* * *}\right) P<0.001$, one-way ANOVA test followed by Tukey's multiple comparison test. $(G, H)$ Frequency of CD11 ${ }^{+} M H C$ II $^{\text {hi }}$ cells $(G)$ and relative expression levels (MFI) of costimulatory molecules $(H)$ in ANGPTL2-stimulated WT BMDCs pretreated with or without DAPT. Frequency is reported as a percentage of total $\mathrm{CD}_{11 \mathrm{c}^{+}}$cells. Expression levels of co-stimulatory molecules in WT BMDCs untreated with both ANGPTL2 and DAPT were set at 1 . Data are means \pm SD; $n=3$ per group. $\left(^{* * *}\right) P<0.001$, one-way ANOVA test followed by Tukey's multiple comparison test.

suggest that ANGPTL2 acts through PIR-B to activate NOTCH signaling in dendritic cells, facilitating their activation and maturation.

Finally, we further assessed expression levels of NOTCH target genes, Hes1, in dendritic cells isolated from kidney tissues of Chd16-Cre/Rosa $a^{\text {LSL-PRCC-TFE3/+ }}$ and Chd16-Cre/Rosa ${ }^{\text {LLL-PRCC-TFE3/+ }} /$ Angptl2 ${ }^{-/-}$mice
(Supplemental Fig. S8B). Hes1 expression levels in dendritic cells derived from Chd16-Cre/Rosa ${ }^{\text {LSL-PRCC-TFE3/+/ }}$ Angpt12 ${ }^{-/-}$mice were significantly lower than those seen in dendritic cells derived from Chd16-Cre/ Rosa ${ }^{\text {LSL-PRCC-TFE3/+ }}$ mice. These results suggest that NOTCH pathway activation in dendritic cells is impaired in Chd16-Cre/Rosa ${ }^{\text {LSL-PRCC-TFE3/+ } / A n g p t 12^{-/-}}$mice and 
that ANGPTL2 derived from host cells in the tumor microenvironment is required to activate NOTCH signaling in dendritic cells.

\section{Discussion}

Here, we demonstrate that ANGPTL2 deficiency in tumor stroma accelerates tumor progression in both a mouse kidney cancer model and a murine syngeneic tumor model. Importantly, we found that the PDGFRa ${ }^{+}$fibroblasts in the tumor microenvironment abundantly express ANGPTL2 and demonstrate that tumor progression in Angpt12 ${ }^{-/-}$mice is inhibited by transfer of

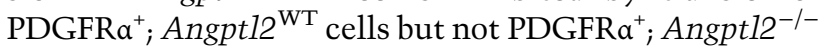
cells. We also found that ANGPTL2 deficiency in tumor stroma leads to decreased infiltration of tumor-specific $\mathrm{CD}^{+} \mathrm{T}$ cells into tumor tissues. Moreover, we present data suggesting that ANGPTL2 activates NOTCH signaling in dendritic cells via PIR-B, and promotes dendritic cell activation and maturation and subsequent $\mathrm{CD}^{+}$ $\mathrm{T}$ cell cross-priming. These findings suggest that PDGFRa $^{+}$fibroblast-derived ANGPTL2 activates dendritic cells via PIR-B-NOTCH signaling, enhancing $\mathrm{CD}^{+} \mathrm{T}$ cell anti-tumor immune responses (Fig. 7 ).

Activated fibroblasts called cancer-associated fibroblasts (CAFs) are particularly abundant stromal cells in the tumor microenvironment (Kalluri and Zeisberg 2006; Cortez et al. 2014). Several studies report that CAFs secrete growth factors, cytokines, and chemokines that promote acquisition of aggressive phenotypes by cancer cells (Mueller and Fusenig 2004; Shiga et al. 2015; Gas- card and Tlsty 2016). Furthermore, CAF abundance in tumor tissues is reportedly associated with poor prognosis of cancer patients (Calon et al. 2015). On the other hand, some studies suggest that some CAF subpopulations inhibit tumor progression: Depletion of $\alpha$-smooth muscle actin $(\mathrm{SMA})^{+} \mathrm{CAFs}$ accelerates tumor growth in a pancreatic cancer mouse model (Özdemir et al. 2014). IL-4 receptorexpressing tumor stromal fibroblasts reportedly facilitate tumor rejection in a murine syngeneic tumor model based on a mouse plasmacytoma cell line (Reynolds et al. 2002). Moreover, PDGFRa ${ }^{+}$CAFs are suggested to play tumorinhibitory roles in colon cancer (Koliaraki et al. 2017). Our data suggests that PDGFRa ${ }^{+}$fibroblasts expressing ANGPTL2 accelerate tumor rejection. Furthermore, analyses using 277 data sets of the PrognoScan database (Mizuno et al. 2009/ revealed that in 27 studies PDGFRA transcript levels in tumor tissues were significantly correlated with clinical outcomes of the cancer patients, and that in 16 of those studies, higher levels of PDGFRA transcripts in tumor tissues, including both tumor and stromal cells, were correlated with better prognosis in cases of lung, breast, colorectal, and ovarian cancer (Supplemental Table S2). Taken together, these suggest findings that the PDGFRa ${ }^{+}$fibroblasts expressing ANGPTL2 could constitute a CAF subpopulation with anti-tumor properties.

Analyses using 230 data sets of the PrognoScan database revealed 28 studies that showed a significant $(P<0.05)$ correlation between the ANGPTL2 expression in tumor tissues, including tumors themselves and surrounding microenvironmental cells, and differential clinical outcomes in patients with lung, breast, cancer, or colorectal cancer (Supplemental Table S3). Interestingly, in 17 of

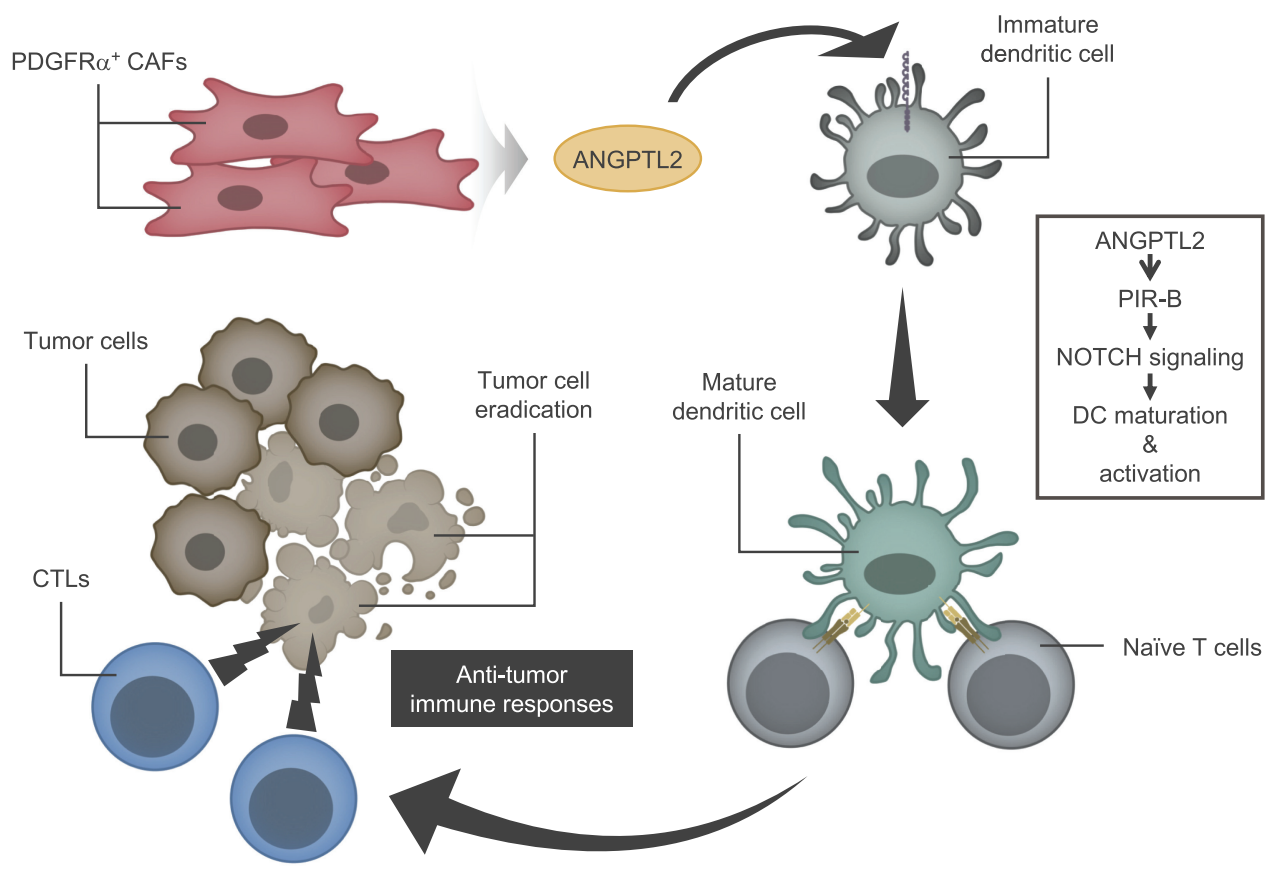

Figure 7. Model proposing regulation of anti-tumor immunity by host ANGPTL2 signaling. In the tumor microenvironment, PDGFR ${ }^{+}$ fibroblasts abundantly express ANGPTL2. PDGFR $\alpha^{+}$fibroblast-derived ANGPTL2 activates dendritic cells via PIR-B-NOTCH signaling, enhancing $\mathrm{CD}^{+} \mathrm{T}$ cell anti-tumor immune responses, contributing to tumor suppression. 
these studies, up-regulated ANGPTL2 expression was correlated with poor prognosis, and in 11, up-regulated ANGPTL2 expression was correlated with more favorable prognosis. Moreover, others have reported that increased ANGPTL2 expression in tumor tissues, including both tumor and stromal cells, is associated with better prognosis of patients with ovarian cancer (Kikuchi et al. 2008). These data suggest overall that ANGPTL2 signaling has complex activity in human cancers, serving both as a tumor promoter and tumor suppressor.

Actually, we and others previously showed that tumorderived ANGPTL2 promotes progression of some cancers, such as skin, lung, breast, pancreatic, and colon cancers, and osteosarcoma (Aoi et al. 2011, 2014; Endo et al. 2012; Horiguchi et al. 2014; Odagiri et al. 2014; Carbone et al. 2015). Tumor cell-derived ANGPTL2 promotes tumor cell migration and invasion, tumor angiogenesis, and the epithelial-mesenchymal transition (EMT), accelerating tumor metastasis (Aoi et al. 2011; Endo et al. 2012; Odagiri et al. 2014). We also previously demonstrated that suppressing ANGPTL2 expression in tumor cells inhibits tumor metastasis in a xenograft mouse model, suggesting that tumor cell-derived ANGPTL2 could be a novel therapeutic target against tumor metastasis (Endo et al. 2012; Odagiri et al. 2014). Furthermore, serum ANGPTL2 reportedly serves as a diagnostic biomarker for some cancers, such as colon and pancreatic cancers (Toiyama et al. 2014; Yoshinaga et al. 2015, 2018). The present study also demonstrated that ANGPTL2 deficiency in renal tubular epithelial cells slows progression of kidney cancer in Xp11 tRCC model mice. Thus, these findings suggest overall that cell-autonomous ANGPTL2 expression in tumor cells has tumor-promoting activity. On the other hand, the present study also provide evidence that tumor stroma-derived ANGPTL2 exhibits anti-tumor activities in both a mouse kidney cancer model and a murine syngeneic tumor model and conclude that tumor- versus tumor stroma-derived ANGPTL2 plays opposing, contextdependent roles in cancer pathology, as has been shown for other signaling factors. For example, nuclear factor$\kappa \mathrm{B}(\mathrm{NF}-\mathrm{\kappa B})$ reportedly functions as a tumor promoter and tumor suppressor in macrophages and hepatocytes, respectively (Maeda et al. 2005; He et al. 2010). In addition, several studies report that changes in post-translational modification regulate activity of various proteins in cancer cells (Netsirisawan et al. 2015; Ho et al. 2016). ANGPTL2 is reportedly glycosylated and secreted into the extracellular space (Kim et al. 1999). Therefore, changes in ANGPTL2 glycosylation between tumor and stromal cells may modulate its function in tumor progression. Future studies are needed to address this possibility.

Previous studies report that PIR-B or LILRB2 functions as an immune inhibitory receptor and that its activation in tumor-infiltrating immune cells, such as myeloidderived suppressor cells (MDSCs), establishes a tumorpermissive microenvironment by accelerating M2-like phenotypes (Ma et al. 2011; Chen et al. 2018). On the other hand, others have demonstrated that Pirb ${ }^{-/}$BMDCs show impaired activation and maturation (Ujike et al. 2002). Accordingly, we showed that ANGPTL2-induced dendritic cell activation and maturation are suppressed in Pirb ${ }^{-1-}$ BMDCs. Therefore, PIR-B may either promote or suppress tumor formation, depending on cell type. Moreover, in the present study we demonstrated that NOTCH activation underlies ANGPTL2-PIR-B signaling-mediated dendritic cell activation and maturation. ANGPTL2-PIR-B signaling reportedly activates calcium/ calmodulin-dependent protein kinase (CAMK) 2 and 4 in hematopoietic stem cells (Zheng et al. 2012). Since CAMK2 also contributes to activation of dendritic cells (Liu et al. 2010), CAMKs might be implicated in ANGPTL2-PIR-B signaling-mediated dendritic cell activation and maturation.

Treatment of BMDCs with rANGPTL2 increased abundance of both full-length and cleaved forms of NOTCH2 proteins in parallel. In addition, rANGPTL2 treatment significantly increased Hes1 expression in BMDCs in a PIR-B-dependent manner. A recent study reported that in hematopoietic stem cells, ANGPTL2-PIR-B interaction promotes NOTCH cleavage by $\gamma$-secretase (Lin et al. 2015). We also demonstrated that treatment with a $\gamma$-secretase inhibitor significantly attenuated ANGPTL2induced dendritic cell activation. Therefore, NOTCH2 activation in dendritic cells may be induced by ANGPTL2-PIR-B interaction. However, it remains unclear how activity of the ANGPTL2-PIR-B axis increases levels of full-length NOTCH2 protein, a question that requires further investigation.

In the present study, we demonstrated that PIR-B, but not integrin $\alpha 5 \beta 1$, is required for ANGPTL2-dependent activation of dendritic cells. However, these results do not negate the idea that ANGPTL2 binds integrin $\alpha 5 \beta 1$ and activates integrin signaling in BMDCs. ANGPTL2 reportedly binds both integrin $\alpha 5 \beta 1$ and PIR-B, while integrin a5 $\beta 1$-mediated ANGPTL2 signaling does not contribute to dendritic cell activation. ANGPTL2-integrin $\alpha 5 \beta 1$ signaling promotes cell migration (Tabata et al. 2009; Kadomatsu et al. 2014) and thus is implicated in dendritic cell migration. Further studies are necessary to investigate roles of ANGPTL2-integrin a5 $\beta 1$ signaling in dendritic cells.

One hallmark of anti-tumor immune responses is a long-term T-cell response. Memory T cells play essential roles in immunological memory and are associated with longer survival of cancer patients (Fridman et al. 2012). Furthermore, it is reported that treatment with immune checkpoint inhibitors enhances T-cell memory formation and function (Pedicord et al. 2011). Here, we demonstrated that ANGPTL2 promotes dendritic cell activation and maturation and subsequent $\mathrm{CD}^{+} \mathrm{T}$-cell cross-priming. However, it remains unclear whether ANGPTL2 functions in induction of long-term T-cell responses. Because Angpt12 ${ }^{-/-}$mice injected with B16-OVA cells show reduced tumor-specific effector $\mathrm{CD}^{+} \mathrm{T}$ cell responses, development of tumor-reactive effector memory $\mathrm{CD}^{+}$ $\mathrm{T}$ cell may also be impaired in Angpt $12^{-/-}$mice. Further studies are needed to determine whether ANGPTL2 contributes to long-term anti-tumor immunity.

In summary, tumor stroma-derived ANGPTL2 inhibits tumor progression by enhancing dendritic cell-mediated 
$\mathrm{CD}^{+} \mathrm{T}$-cell anti-tumor immune responses, activities that contrast with tumor progression associated with tumorcell-derived ANGPTL2. Our findings support the idea that ANGPTL2 signaling has a dual function in cancer, and they provide novel insight into regulation of anti-tumor immunity.

\section{Materials and methods}

Animals

Genetically engineered mice used in this study were: Angpt12-/mice (Tabata et al. 2009) on a C57BL/6N background, Pirb ${ }^{-/-}$ mice (Endo et al. 2008) (kindly provided by Dr. Takai [Tohoku University]) on a C57BL/6N background, Rosa ${ }^{\text {LSL-PRCC-TFE3/+ }}$ mice on a C57BL/6N background (Kurahashi et al. 2019), Angpt $12^{\mathrm{F} / \mathrm{F}}$ mice (Tian et al. 2016) on a C57BL/6J background, and $\mathrm{Tg}$ mice overexpressing $\mathrm{Cre}$ driven by the murine Cadherin16 promoter (Cdh16-Cre) (Shao et al. 2002) on a C57BL/ $6 \mathrm{~N}$ background. Male $\mathrm{C} 57 \mathrm{BL} / 6 \mathrm{~N}$ mice were purchased from CLEA (Japan). All experimental procedures were approved by the Ethics Review Committee for Animal Experimentation of Kumamoto University.

Generation of translocation renal cell carcinoma model mice

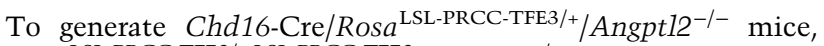
Rosa $a^{\text {LSL-PRCC-TFE3/ LSL-PRCC-TFE3 }} /$ Angpt12 $^{-/+}$female mice were mated with Chd16-Cre/ Angpt12 ${ }^{-/}$male mice. To generate Chd16-Cre/Rosa $a^{\text {LSL-PRCC-TFE } /+} /$ Angptl2 $^{\mathrm{F} / \mathrm{F}}$ mice, Rosa $^{\text {LSL-PRCC-TFE } 3 /+} /$ Angpt $12^{\mathrm{F} / \mathrm{F}}$ female mice were mated with Chd16-Cre/Angpt12 ${ }^{\mathrm{F} / \mathrm{F}}$ male mice.

Cell culture

The human renal tubular epithelial cell line HK-2 harboring PRCC-TFE3, NONO-TFE3, or SFPQ-TFE3 fusion genes was maintained in DMEM/F-12 containing $10 \%$ FCS, $0.8 \mu \mathrm{g} / \mathrm{mL}$ puromycin, and $10 \mu \mathrm{g} / \mathrm{mL}$ blasticidin. To induce fusion gene expression, cells were treated with $100 \mathrm{ng} / \mathrm{mL}$ doxycycline for $48 \mathrm{~h}$.

C2C12 cells, 3T3-L1 cells, and B16-OVA melanoma cells, which express a non-secreted form of chicken ovalbumin (OVA) as a surrogate tumor antigen, were cultured in DMEM (Wako) supplemented with $10 \%$ fetal calf serum (FCS), penicillin, and streptomycin (Wako) at $37^{\circ} \mathrm{C}$ in a humidified $5 \% \mathrm{CO}_{2}$ atmosphere.

\section{Tumor transplantation}

B16-OVA melanoma cells $\left(2 \times 10^{5}\right)$ in $50 \mu \mathrm{L}$ PBS were injected subcutaneously into both back flanks of $8-12$-wk-old mice. Tumor growth was measured with calipers to calculate tumor volume (= width $^{2} \times$ height $\left.\times 0.523\right)$. In survival analysis, to minimize suffering, mice were euthanized when the tumor diameter exceeded $15 \mathrm{~mm}$.

For coinjection of tumor cells and fibroblasts, PDGFRa ${ }^{+}$cells were isolated from tumor tissues of mice bearing B16-OVA tumors at $21 \mathrm{~d}$ after implantation by magnetic-activated cell sorting (MACS) using a CD140a (PDGFRa) microbeads kit (Miltenyi Biotec). Isolated PDGFRa ${ }^{+}\left(2 \times 10^{5}\right)$ and B16-OVA $\left(2 \times 10^{5}\right)$ cells were coinjected subcutaneously into right back flanks of 8 -wk-old mice.

For analysis of Angpt12 mRNA expression in tumor stromal cells, B16-OVA cells $\left(2 \times 10^{5}\right)$ were injected subcutaneously into both back flanks of 8-wk-old mice. At $17 \mathrm{~d}$ after implantation, tumor stromal cells were isolated from pooled three tumor specimens by MACS using a CD45, CD31, or CD140a microbeads kit and/or a tumor-associated fibroblast isolation kit (Miltenyi Biotec). Isolated cells were subjected to qRT-PCR analysis.

\section{Histology, immunohistochemistry, immunofluorescence}

For histological analysis, tumor tissue samples were fixed with $4 \%$ paraformaldehyde, embedded in paraffin, sectioned with a microtome, and stained with hematoxylin and eosin (H\&E).

For TFE3 immunohistochemistry, deparaffinized sections were pretreated with $3 \% \mathrm{H}_{2} \mathrm{O}_{2}$ in Tris-buffered saline (TBS) (pH 7.6) to inhibit endogenous peroxidases. Sections were then heated to $121^{\circ} \mathrm{C}$ for $15 \mathrm{~min}$ in Target Retrieval Solution (Dako), blocked with $5 \%$ goat serum, and incubated with anti-TFE3 antibody (1:100, Sigma-Aldrich, HPA023881) overnight at $4^{\circ} \mathrm{C}$. After TBS washing, sections were incubated with EnVision + System-HRP Labelled Polymer Anti-Rabbit (Dako) as secondary antibody for $1 \mathrm{~h}$ at room temperature. Sections were washed with TBS and peroxidase activity was visualized by incubation with a 3,3-diaminobenzidine solution followed by hematoxylin counterstaining.

Immunohistochemical staining for mouse ANGPTL2 was performed as described (Horiguchi et al. 2017). For double immunofluorescent staining, frozen sections were fixed in pre-cold acetone for $20 \mathrm{~min}$ and then blocked for $20 \mathrm{~min}$ with $5 \%$ serum at room temperature. Samples were incubated with anti-mouse ANGPTL2 rabbit monoclonal antibody (1:50) (Motokawa et al. 2016) and antibody for CD45 (1:150, BD, BD550539), ER-TR7 (1:100, Novus biologicals), CD31 (1:100, BD, 555444), CD68 (1:100, Bio-Rad, MCA1957), PDGFRa (1:100, BioLegend, 135909), or PDGFR $\beta$ (1:100, eBioscience, 14-1402-81) overnight at $4^{\circ} \mathrm{C}$. For ANGPTL2, staining was performed using a Tyramide Signal Amplification (TSA) kit (Perkin Elmer). For CD45, ER-TR7, CD31, CD68 PDGFR $\alpha$, and PDGFR $\beta$, samples were incubated for $60 \mathrm{~min}$ with Alexa Fluor 488-conjugated secondary antibody (Thermo Fisher Scientific, 1:200) at room temperature. Nuclei were stained for 20 min with DAPI.

\section{Kidney tissue digestion for flow cytometry and cell isolation}

The kidney was minced into $1-\mathrm{mm}^{3}$ pieces and digested with $1 \mathrm{mg} / \mathrm{mL}$ collagenase $\mathrm{D}$ and $0.5 \mathrm{mg} / \mathrm{mL}$ dispase for $30 \mathrm{~min}$ on a shaking $37^{\circ} \mathrm{C}$ incubator. Tissue was then passed through a $100-$ $\mu \mathrm{m}$ cell strainer by mechanical disruption. Digested tissue was treated with red-blood-cell lysis buffer $\left(0.15 \mathrm{M} \mathrm{NH}_{4} \mathrm{Cl}, 10 \mathrm{mM}\right.$ $\mathrm{KHCO}_{3}$, and $1 \mathrm{mM}$ EDTA, $\mathrm{pH}$ 7.2-7.4). The cell suspension was centrifuged and suspended in MACS buffer (Miltenyi Biotec).

To isolate dendritic cells, CD11 $\mathrm{c}^{+}$dendritic cells were isolated from kidney tissues of Chd16-Cre/Rosa ${ }^{\text {LSL-PRCC-TFE3/+ }}$ mice and

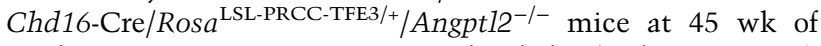
age by MACS using a CD11c microbeads kit (Miltenyi Biotec), and isolated cells were subjected to qRT-PCR analysis.

\section{Flow cytometry}

Cells were suspended in MACS buffer and incubated with antiCD16/32 mAb (BioLegend, 101310) for Fc receptor blocking. Cells were stained with the following fluorochrome-conjugated antibodies: PerCP/Cy5.5 anti-CD45 (BioLegend, 103131), PE anti-CD45 (BioLegend, 109807), FITC anti-CD8 (MBL, D271-4), APC anti-CD8 (BioLegend, 100712), PE anti-GzmB (BD, 561142), PerCP/Cy5.5 anti-CD11c (BioLegend, 117328), PE/Cy7 anti-MHC II (BioLegend, 107630), PE anti-CD86 (BioLegend, 105008), APC anti-CD80 (BioLegend, 104713), FITC anti-CD40 
(BioLegend, 102905), PE anti-ITGa5 (BioLegend, 103805), antiITGa4 (BioLegend, 103607), anti-ITGav (BioLegend, 104105), anti-ITG $\beta 1$ (BioLegend, 102207), anti-ITG $\beta 2$ (BioLegend, 101407), anti-ITG $\beta 3$ (BioLegend, 104307), and anti-PIR-A/B (BD, $550349)$. For analysis of OVA-specific $\mathrm{CD} 8^{+} \mathrm{T}$ cells, cells were incubated with PE-conjugated $\mathrm{H}-2 \mathrm{~K}^{\mathrm{b}}$-SIINFEKL-tetramer (MBL), according to the manufacturer's instructions. Stained cells were analyzed by BD FACSVerse (BD bioscience). Data analysis was performed using FlowJo software (Treestar).

Total RNA extraction and real-time quantitative RT-PCR

Total RNA was isolated from cells and tissues using TRIzol regent (Invitrogen). DNase-treated RNA was reversed-transcribed with a PrimeScript RT regent Kit (Takara Bio). PCR products were analyzed using a Thermal Cycler Dice Real Time System (Takara Bio). PCR primer sequences (forward and reverse, respectively) were 5'-GACCATCACTGTCAAAGAGTTTCTAGAT-3'

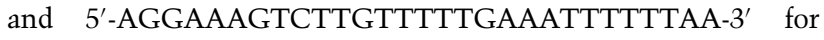
mouse I112p40; 5'- GGAGGTTGGACTGTCATCCAGAG-3' and 5'-GCCTTGGTTCGTCAGCCAGTA-3' for mouse Angpt12; 5'-AAAGACGGCCTCTGAGCAC- $3^{\prime}$ and 5'-GGTGGTTCAC AGTCATTTCCA-3' for mouse Hes1; 5'-GGTACCCAGTGCC TTTGAGAA- $3^{\prime}$ and $5^{\prime}$-ATGCTCAGATAACGGGCAAC-3' for mouse Hey1; 5'-TTCTGGCCAACGGTCTAGACAAC-3' and 5'-CCAGTGGTCTTGGTGTGCTGA-3' for mouse Rps18. Relative transcript abundance was normalized to that of Rps18 mRNA.

\section{$B M D C$ culture and treatment}

Mouse BMDCs were differentiated and cultured as described (Jing et al. 2003) with minor modifications. Briefly, BM cells were obtained from femur and tibia and cultured in RPMI 1640 medium (Wako) containing 10\% FCS, penicillin, streptomycin, $50 \mu \mathrm{M}$ 2-mercaptoethanol, and $20 \mathrm{ng} / \mathrm{mL}$ GM-CSF (BioLegend). After $3 \mathrm{~d}$, an equal volume of complete medium containing $20 \mathrm{ng} / \mathrm{mL}$ GM-CSF was added. At day 6, non-adherent cells were collected and used as immature BMDCs. In some experiments, immature BMDCs were treated for $6 \mathrm{~h}$ with vehicle or recombinant mouse ANGPTL2 protein $(5 \mu \mathrm{g} / \mathrm{mL})$. For anti-integrin antibody treatment, immature BMDCs were pretreated with $20 \mu \mathrm{g} / \mathrm{mL}$ isotype control IgG (Biolegend, 400916) or antibody against mouse integrin a5 (Biolegend, 103908) or mouse integrin $\beta 1$ (Biolegend, 102210) for $60 \mathrm{~min}$ and then treated for $6 \mathrm{~h}$ with recombinant mouse ANGPTL2 protein in the presence of each antibody. For DAPT treatment, immature BMDCs were pretreated with 20 $\mu M$ DAPT (Wako) for $60 \mathrm{~min}$ and then treated for $6 \mathrm{~h}$ with recombinant mouse ANGPTL2 protein in the presence of DAPT.

In vitro cross-presentation assay

OVA presentation in the context of $\mathrm{H}-2 \mathrm{~K}^{\mathrm{b}}$ was assessed in vitro using the B3Z CD8 ${ }^{+} \mathrm{T}$ cell hybridomas (Karttunen et al. 1992) as described (Ghosh and Shapiro 2012). BMDCs were stimulated with LPS $(10 \mathrm{ng} / \mathrm{mL})$ or recombinant ANGPTL2 protein $(5 \mu \mathrm{g} /$ $\mathrm{mL}$ ) for $6 \mathrm{~h}$. After stimulation, BMDCs were cultured with B3Z cells at a $1: 1$ ratio for $24 \mathrm{~h}$ in the presence of $10 \mu \mathrm{g} / \mathrm{mL}$ OVA protein. $\beta$-Galactosidase activity was detected by adding chlorophenol red- $\beta$-D-galactopyranoside (CPRG) and absorbance was measured at $595 \mathrm{~nm}$. B3Z activation was expressed as an increase in absorbance relative to B3Z cells incubated with unstimulated BMDCs in the absence of OVA protein. $\beta$-Galactosidase activity in B3Z cells without BMDCs in the presence of OVA protein served as background control.
In vivo dendritic cell immunization and adoptive transfer

WT BMDCs were stimulated with $5 \mu \mathrm{g} / \mathrm{mL}$ recombinant mouse ANGPTL2 protein for $4 \mathrm{~h}$ and then pulsed with OVA peptide SIINFEKL (MBL) for $6 \mathrm{~h}$ more. After washing with PBS, BMDCs were suspended in PBS. For adoptive transfer experiments, B16OVA melanoma cells $\left(2 \times 10^{5}\right)$ were injected subcutaneously into both back flanks of 8 -wk-old C57BL/6 male mice, and mice were randomly divided into four groups. On days 3 and 8 after implantation, mice were injected subcutaneously with PBS or $1 \times 10^{6}$ unstimulated BMDCs, unstimulated BMDCs pulsed with OVA peptide, or ANGPTL2-stimulated BMDCs pulsed with OVA peptide. Mice injected with PBS served as control. Tumor growth was measured with calipers to calculate tumor volume $\left(=\right.$ widt $^{2} \times$ height $\times 0.523$ ). For survival analysis, to minimize suffering, mice were euthanized when the tumor diameter exceeded $15 \mathrm{~mm}$.

\section{Immunoblot analysis}

Solubilized proteins were subjected to SDS-PAGE, and proteins were electrotransfered to nitrocellulose membranes. Immunoblotting was performed with antibodies against ANGPTL2 (1:1000, R\&D Systems, BAF1444), NOTCH2 (1:1000, Cell Signaling Technology, \#5732), GAPDH (1:1000, Cell Signaling Technology, \#5174), HA-tag (1:1000, Cell Signaling Technology, \#3724), and Hsc70 (1:2000, Santa Cruz Biotechnology, \#sc7298). Immunodetection was carried out using an ECL kit (GE Healthcare) according to the manufacturer's protocol.

\section{DNA microarray analysis}

HK2 cell lines, which express HA-PRCC-TFE3, HA-SFPQ-TFE3, or HA-NONO-TFE3 doxycycline-dependently, were established by two sequential lentiviral transductions using the full-length rtTA3(Tet-on) gene (Takara) and the HA-PRCC-TFE3, HASFPQ-TFE3, or HA-NONO-TFE3 genes under control of the TRE-tight promoter. Cells were cultured in Advanced DMEM/ F-12 with $1.5 \%$ Tetracycline-Free Fetal Bovine Serum (Takara) and selection antibiotics, $2 \mu \mathrm{g} / \mathrm{mL}$ Blasticidin S, and $0.8 \mu \mathrm{g} / \mathrm{mL}$ Puromycin. For gene expression profiling, HK2 lines were cultured with or without $200 \mathrm{ng} / \mathrm{mL}$ doxycycline. Total RNA was isolated from cells using TRIzol reagent (Invitrogen). cDNA preparation and hybridization were performed according to the manufacturer's protocol (Affymetrix). Affymetrix GeneChip Human Genome U133 Plus 2.0 arrays were applied. RMA-based data normalization and subsequent data analysis, including PCA and ANOVA, were performed with Partek Genomics Suite 6.6.

Quantification of serum BUN

BUN concentration in mouse sera was determined using a UREA NITROGEN (BUN) Colorimetric Detection Kit (ARBOR ASSAYS), according to the manufacturer's instructions.

\section{Statistical analysis}

Statistical analyses were performed using GraphPad prism 7 software (GraphPad Software). Statistical parameters and methods are reported in respective figures and figure legends. Results with $P$-values $<0.05$ were considered significant. $\left({ }^{*}\right) P<0.05$; $\left({ }^{* *}\right)$ $\left.P<0.01 ;\left(^{* * *}\right) P<0.001\right)$. Comparisons between two groups were performed using unpaired two-tailed $t$-test or the Mann-Whitney $U$-test. Comparisons between three or more groups were performed using one-way ANOVA with Tukey's multiple comparison test. For comparisons with two or more independent 
variable factors, we used two-way ANOVA followed by Bonferroni's multiple test. Survival rate was analyzed by log-rank test.

Data resources

Patient epidemiological data were obtained from the PrognoScan database: See Supplemental Tables S2 and S3.

\section{Acknowledgments}

We thank Kiyoka Tabu, Noriko Shirai, and Sayomi Iwaki for technical assistance. We also thank Nilabh Shastri (Johns Hopkins Medical Institute) for the gift of the B3Z cells. This work was supported by the Scientific Research Fund of the Ministry of Education, Culture, Sports, Science, and Technology (MEXT) of Japan (grant 18K07236 to T.K., grant 18K15246 to H.H.), the Core Research for Evolutional Science and Technology (CREST) program of the Japan Science and Technology Agency (JST) (grant 13417915 to Y.O.), the CREST program of the Japan Agency for Medical Research and Development (AMED) (grant JP18gm0610007 to Y.O.), the Center for Metabolic Regulation of Healthy Aging (CMHA) (T.K.), the Shin-Nihon Foundation of Advanced Medical Research (T.K.), and the Takeda Science Foundation (T.K.).

Author contributions: H.H. designed the study, performed and analyzed most of experiments, and wrote the manuscript. T.K. designed the study, performed and analyzed experiments, and wrote the manuscript. R.K. and C.H. collected mouse experimental data of tRCC model. K.M. and H.O. provided Angpt12 mutant mice. M.B. and W.M.L. provided a plasmid encoding PRCC-TFE3 and performed DNA microarray analysis. K.T. provided recombinant ANGPTL2 protein. K.A. generated Xp11 tRCC model mice. T.T. provided Pirb $^{-1-}$ mice. T.K. provided advice on the study. T.M. designed and supervised the study, and wrote the manuscript. Y.O. coordinated, designed, and supervised the study, and wrote the manuscript. All authors discussed the data and commented on the manuscript.

\section{References}

Aoi J, Endo M, Kadomatsu T, Miyata K, Nakano M, Horiguchi H, Ogata A, Odagiri H, Yano M, Araki K, et al. 2011. Angiopoietin-like protein 2 is an important facilitator of inflammatory carcinogenesis and metastasis. Cancer Res 71: 7502-7512. doi:10.1158/0008-5472.CAN-11-1758

Aoi J, Endo M, Kadomatsu T, Miyata K, Ogata A, Horiguchi H, Odagiri H, Masuda T, Fukushima S, Jinnin M, et al. 2014. Angiopoietin-like protein 2 accelerates carcinogenesis by activating chronic inflammation and oxidative stress. Mol Cancer Res 12: 239-249. doi:10.1158/1541-7786.MCR-13-0336

Baba M, Furuya M, Motoshima T, Lang M, Funasaki S, Ma W, Sun H-W, Hasumi H, Huang Y, Kato I, et al. 2019. TFE3Xp11.2 translocation renal cell carcinoma mouse model reveals novel therapeutic targets and identifies GPNMB as a diagnostic marker for human disease. Mol Cancer Res 17: 1613-1626. doi:10.1158/1541-7786.MCR-18-1235

Balkwill FR, Capasso M, Hagemann T. 2012. The tumor microenvironment at alance. J Cell Sci 125: 5591-5596. doi:10.1242/ jcs. 116392

Binnewies M, Roberts EW, Kersten K, Chan V, Fearon DF, Merad M, Coussens LM, Gabrilovich DI, Ostrand-Rosenberg S, Hedrick CC, et al. 2018. Understanding the tumor immune microenvironment (TIME) for effective therapy. Nat Med 24: 541-550. doi:10.1038/s41591-018-0014-x
Brown D, Trowsdale I, Allen R. 2004. The LILR family: modulators of innate and adaptive immune pathways in health and disease. Tissue Antigens 64: 215-225. doi:10.1111/j.00012815.2004.00290.x

Bu L, Baba H, Yoshida N, Miyake K, Yasuda T, Uchihara T, Tan P, Ishimoto T. 2019. Biological heterogeneity and versatility of cancer-associated fibroblasts in the tumor microenvironment. Oncogene 38: 4887-4901. doi:10.1038/s41388-019-0765-y

Calon A, Lonardo E, Berenguer-Llergo A, Espinet E, HernandoMomblona X, Iglesias M, Sevillano M, Palomo-Ponce S, Tauriello DVF, Byrom D, et al. 2015. Stromal gene expression defines poor-prognosis subtypes in colorectal cancer. Nat Genet 47: 320-329. doi:10.1038/ng.3225

Carbone C, Piro G, Fassan M, Tamburrino A, Mina MM, Zanotto M, Chiao PJ, Bassi C, Scarpa A, Tortora G, et al. 2015. An angiopoietin-like protein 2 autocrine signaling promotes EMT during pancreatic ductal carcinogenesis. Oncotarget 6: 13822-13834. doi:10.18632/oncotarget.2635

Chen H-M, van der Touw W, Wang YS, Kang K, Mai S, Zhang J, Alsina-Beauchamp D, Duty JA, Mungamuri SK, Zhang B, et al. 2018. Blocking immunoinhibitory receptor LILRB2 reprograms tumor-associated myeloid cells and promotes antitumor immunity. J Clin Invest 128: 5647-5662. doi:10.1172/ JCI97570

Colonna M, Nakajima H, Cella M. 2000. A family of inhibitory and activating Ig-like receptors that modulate function of lymphoid and myeloid cells. Semin Immunol 12: 121-127. doi:10 $.1006 / \mathrm{smim} .2000 .0214$

Cortez E, Roswall P, Pietras K. 2014. Functional subsets of mesenchymal cell types in the tumor microenvironment. Semin Cancer Biol 25: 3-9. doi:10.1016/j.semcancer.2013.12.010

Ellis CL, Eble JN, Subhawong AP, Martignoni G, Zhong M, Ladanyi M, Epstein JI, Netto GJ, Argani P. 2014. Clinical heterogeneity of Xp11 translocation renal cell carcinoma: impact of fusion subtype, age, and stage. Mod Pathol 27: 875-886. doi:10.1038/modpathol.2013.208

Emon B, Bauer J, Jain Y, Jung B, Saif T. 2018. Biophysics of tumor microenvironment and cancer metastasis - a mini review. Comput Struct Biotechnol J 16: 279-287. doi:10.1016/j.csbj .2018 .07 .003

Endo S, Sakamoto Y, Kobayashi E, Nakamura A, Takai T. 2008. Regulation of cytotoxic T lymphocyte triggering by PIR-B on dendritic cells. Proc Natl Acad Sci 105: 14515-14520. doi:10 $.1073 /$ pnas.0804571105

Endo $M$, Nakano $M$, Kadomatsu $T$, Fukuhara $S$, Kuroda $H$, Mikami S, Hato T, Aoi J, Horiguchi H, Miyata K, et al. 2012. Tumor cell-derived angiopoietin-like protein ANGPTL2 is a critical driver of metastasis. Cancer Res 72: 1784-1794. doi:10.1158/0008-5472.CAN-11-3878

Fridman WH, Pagès F, Sautès-Fridman C, Galon J. 2012. The immune contexture in human tumours: impact on clinical outcome. Nat Rev Cancer 12: 298-306. doi:10.1038/nrc3245

Gajewski TF, Schreiber H, Fu Y-X. 2013. Innate and adaptive immune cells in the tumor microenvironment. Nat Immunol 14: 1014-1022. doi:10.1038/ni.2703

Gascard P, Tlsty TD. 2016. Carcinoma-associated fibroblasts: orchestrating the composition of malignancy. Genes Dev 30: 1002-1019. doi:10.1101/gad.279737.116

Ghosh M, Shapiro L. 2012. In vitro Ag cross-presentation and in vivo Ag cross-presentation by dendritic cells in the mouse. Bio Protoc 2. doi:10.21769/BioProtoc.305

Guilliams M, Scott CL. 2018. 'NOTCHing up' the in vitro production of dendritic cells. Trends Immunol 39: 765-767. doi:10.1016/j.it.2018.08.002 
Ha SY, Yeo SY, Xuan YH, Kim SH. 2014. The prognostic significance of cancer-associated fibroblasts in esophageal squamous cell carcinoma. PLoS One 9: e99955. doi:10.1371/journal.pone .0099955

Hanahan D, Coussens LM. 2012. Accessories to the crime: functions of cells recruited to the tumor microenvironment. Cancer Cell 21: 309-322. doi:10.1016/j.ccr.2012.02.022

Hato T, Tabata M, Oike Y. 2008. The role of angiopoietin-like proteins in angiogenesis and metabolism. Trends Cardiovasc Med 18: 6-14. doi:10.1016/j.tcm.2007.10.003

He G, Yu GY, Temkin V, Ogata H, Kuntzen C, Sakurai T, Sieghart W, Peck-Radosavljevic M, Leffert HL, Karin M. 2010. Hepatocyte IKK $\beta / \mathrm{NF}-\mathrm{\kappa B}$ inhibits tumor promotion and progression by preventing oxidative stress-driven STAT3 activation. Cancer Cell 17: 286-297. doi:10.1016/j.ccr.2009.12.048

Ho WL, Hsu WM, Huang MC, Kadomatsu K, Nakagawara A. 2016. Protein glycosylation in cancers and its potential therapeutic applications in neuroblastoma. I Hematol Oncol 9: 100. doi:10.1186/s13045-016-0334-6

Horiguchi $H$, Endo M, Miyamoto $Y$, Sakamoto $Y$, Odagiri $H$, Masuda T, Kadomatsu T, Tanoue H, Motokawa I, Terada K, et al. 2014. Angiopoietin-like protein 2 renders colorectal cancer cells resistant to chemotherapy by activating spleen tyrosine kinase-phosphoinositide 3-kinase-dependent anti-apoptotic signaling. Cancer Sci 105: 1550-1559. doi:10.1111/cas .12554

Horiguchi H, Endo M, Kawane K, Kadomatsu T, Terada K, Morinaga J, Araki K, Miyata K, Oike Y. 2017. ANGPTL2 expression in the intestinal stem cell niche controls epithelial regeneration and homeostasis. EMBO J 36: 409-424. doi:10.15252/ embj.201695690

Jing H, Vassiliou E, Ganea D. 2003. Prostaglandin E2 inhibits production of the inflammatory chemokines CCL3 and CCL4 in dendritic cells. J Leukoc Biol 74: 868-879. doi:10.1189/jlb .0303116

Kadomatsu T, Endo M, Miyata K, Oike Y. 2014. Diverse roles of ANGPTL2 in physiology and pathophysiology. Trends Endocrinol Metab 25: 245-254. doi:10.1016/j.tem.2014.03.012

Kalluri R, Zeisberg M. 2006. Fibroblasts in cancer. Nat Rev Cancer 6: 392-401. doi:10.1038/nrc1877

Karttunen J, Sanderson S, Shastri N. 1992. Detection of rare antigen-presenting cells by the lacZ T-cell activation assay suggests an expression cloning strategy for T-cell antigens. Proc Natl Acad Sci 89: 6020-6024. doi:10.1073/pnas.89.13.6020

Kauffman EC, Ricketts CI, Rais-Bahrami S, Yang Y, Merino MJ, Bottaro DP, Srinivasan R, Linehan WM. 2014. Molecular genetics and cellular features of TFE3 and TFEB fusion kidney cancers. Nat Rev Urol 11: 465-475. doi:10.1038/nrurol.2014 .162

Kikuchi R, Tsuda H, Kozaki K-i, Kanai Y, Kasamatsu T, Sengoku K, Hirohashi S, Inazawa J, Imoto I. 2008. Frequent inactivation of a putative tumor suppressor, angiopoietin-like protein 2, in ovarian cancer. Cancer Res 68: 5067-5075. doi:10.1158/00085472.CAN-08-0062

Kim I, Moon SO, Koh KN, Kim H, Uhm CS, Kwak HJ, Kim NG, Koh GY. 1999. Molecular cloning, expression, and characterization of angiopoietin-related protein. Angiopoietin-related protein induces endothelial cell sprouting. I Biol Chem 274: 26523-26528. doi:10.1074/jbc.274.37.26523

Kirkling ME, Cytlak U, Lau CM, Lewis KL, Resteu A, KhodadadiJamayran A, Siebel CW, Salmon H, Merad M, Tsirigos A, et al. 2018. Notch signaling facilitates in vitro generation of crosspresenting classical dendritic cells. Cell Rep 23: 36583672.e6. doi:10.1016/j.celrep.2018.05.068
Koliaraki V, Pallangyo CK, Greten FR, Kollias G. 2017. Mesenchymal cells in colon cancer. Gastroenterology 152: 964 979. doi:10.1053/j.gastro.2016.11.049

Kubota Y, Oike Y, Satoh S, Tabata Y, Niikura Y, Morisada T, Akao M, Urano T, Ito Y, Miyamoto T, et al. 2005. Isolation and expression patterns of genes for three angiopoietin-like proteins, Angptl1, 2 and 6 in zebrafish. Gene Expr Patterns 5: 679-685. doi:10.1016/j.modgep.2005.02.006

Kurahashi R, Kadomatsu T, Baba M, Hara C, Itoh H, Miyata K, Endo M, Morinaga J, Terada K, Araki K, et al. 2019. MiR204-5p: a novel candidate urinary biomarker of Xp11.2 translocation renal cell carcinoma. Cancer Sci 110: 1897-1908.

Lebrun J-J. 2012. The dual role of TGF $\beta$ in human cancer: from tumor suppression to cancer metastasis. ISRN Mol Biol 2012: 381428.

Lewis KL, Caton ML, Bogunovic M, Greter M, Grajkowska LT, $\mathrm{Ng} \mathrm{D,} \mathrm{Klinakis} \mathrm{A,} \mathrm{Charo} \mathrm{IF,} \mathrm{Jung} \mathrm{S,} \mathrm{Gommerman} \mathrm{JL,} \mathrm{et} \mathrm{al.}$ 2011. Notch2 receptor signaling controls functional differentiation of dendritic cells in the spleen and intestine. Immunity 35: 780-791. doi:10.1016/j.immuni.2011.08.013

Lin MI, Price EN, Boatman S, Hagedorn EJ, Trompouki E, Satishchandran S, Carspecken CW, Uong A, DiBiase A, Yang S, et al. 2015. Angiopoietin-like proteins stimulate HSPC development through interaction with Notch receptor signaling. Elife 4: e05544. doi:10.7554/eLife.05544

Liu X, Zhan Z, Xu L, Ma F, Li D, Guo Z, Lin N, Cao X. 2010. MicroRNA-148/152 impair innate response and antigen presentation of TLR-triggered dendritic cells by targeting CaMKIIa. I Immunol 185: 7244-7251. doi:10.4049/jimmunol .1001573

Ma G, Pan P-Y, Eisenstein S, Divino CM, Lowell CA, Takai T, Chen S-H. 2011. Paired immunoglobin-like receptor-B regulates the suppressive function and fate of myeloid-derived suppressor cells. Immunity 34: 385-395. doi:10.1016/j.immuni .2011 .02 .004

Maeda S, Kamata H, Luo JL, Leffert H, Karin M. 2005. IKK $\beta$ couples hepatocyte death to cytokine-driven compensatory proliferation that promotes chemical hepatocarcinogenesis. Cell 121: 977-990. doi:10.1016/j.cell.2005.04.014

Massagué J. 2008. TGF $\beta$ in cancer. Cell 134: 215-230. doi:10 $.1016 /$ j.cell.2008.07.001

Masuda T, Endo $M$, Yamamoto $Y$, Odagiri $H$, Kadomatsu $T$, Nakamura T, Tanoue H, Ito H, Yugami M, Miyata K, et al. 2015. ANGPTL2 increases bone metastasis of breast cancer cells through enhancing CXCR4 signaling. Sci Rep 5: 9170. doi:10.1038/srep09170

Mizuno H, Kitada K, Nakai K, Sarai A. 2009. PrognoScan: a new database for meta-analysis of the prognostic value of genes. BMC Med Genomics 2: 18. doi:10.1186/1755-8794-2-18

Motokawa I, Endo M, Terada K, Horiguchi H, Miyata K, Kadomatsu T, Morinaga J, Sugizaki T, Ito T, Araki K, et al. 2016. Interstitial pneumonia induced by bleomycin treatment is exacerbated in Angptl2 -deficient mice. Am I Physiol Cell Mol Physiol 311: L704-L713. doi:10.1152/ajplung.00005.2016

Mueller MM, Fusenig NE. 2004. Friends or foes-bipolar effects of the tumour stroma in cancer. Nat Rev Cancer 4: 839-849. doi: $10.1038 /$ nrc1477

Netsirisawan P, Chokchaichamnankit D, Srisomsap C, Svasti J, Champattanachai V. 2015. Proteomic analysis reveals aberrant $O$-GlcNAcylation of extracellular proteins from breast cancer cell secretion. Cancer Genomics Proteomics 12: 201209.

Odagiri H, Kadomatsu T, Endo M, Masuda T, Morioka MS, Fukuhara S, Miyamoto T, Kobayashi E, Miyata K, Aoi J, et al. 2014. The secreted protein ANGPTL2 promotes metastasis of 
osteosarcoma cells through integrin $\alpha_{5} \beta_{1}$ p38 MAPK, and matrix metalloproteinases. Sci Signal 7: ra7. doi:10.1126/scisig nal.2004612

Oike Y, Yasunaga K, Ito Y, Matsumoto S-I, Maekawa H, Morisada T, Arai F, Nakagata N, Takeya M, Masuho Y, et al. 2003. Angiopoietin-related growth factor (AGF) promotes epidermal proliferation, remodeling, and regeneration. Proc Natl Acad Sci 100: 9494-9499. doi:10.1073/pnas.1531901100

Özdemir BC, Pentcheva-Hoang T, Carstens JL, Zheng X, Wu C-C, Simpson TR, Laklai H, Sugimoto H, Kahlert C, Novitskiy SV, et al. 2014. Depletion of carcinoma-associated fibroblasts and fibrosis induces immunosuppression and accelerates pancreas cancer with reduced survival. Cancer Cell 25: 719-734. doi:10 $.1016 /$ j.ccr.2014.04.005

Pedicord VA, Montalvo W, Leiner IM, Allison JP. 2011. Single dose of anti-CTLA-4 enhances CD8+ T-cell memory formation, function, and maintenance. Proc Natl Acad Sci 108: 266-271. doi:10.1073/pnas.1016791108

Reynolds HE, Espinoza RM, Mönckeberg FG, Graf SJ. 2002. Síndrome hemolítico-urémico y Streptococo pneumoniae: report of one case. Rev Med Chil 130: 677-680. doi:10.4067/S003498872002000600012

Ross H, Argani P. 2010. Xp11 translocation renal cell carcinoma. Pathology 42: 369-373. doi:10.3109/00313021003767348

Roswall P, Pietras K. 2012. Of mice and men: a comparative study of cancer-associated fibroblasts in mammary carcinoma. Ups J Med Sci 117: 196-201. doi:10.3109/03009734.2012.658973

Shao X, Somlo S, Igarashi P. 2002. Epithelial-specific Cre/lox recombination in the developing kidney and genitourinary tract. J Am Soc Nephrol 13: 1837-1846. doi:10.1097/01.ASN .0000016444 .90348 .50

Shiga K, Hara M, Nagasaki T, Sato T, Takahashi H, Takeyama H. 2015. Cancer-associated fibroblasts: their characteristics and their roles in tumor growth. Cancers (Basel) 7: 2443-2458. doi: $10.3390 /$ cancers 7040902

Sugimoto H, Mundel TM, Kieran MW, Kalluri R. 2006. Identification of fibroblast heterogeneity in the tumor microenvironment. Cancer Biol Ther 5: 1640-1646. doi:10.4161/cbt.5.12 .3354
Tabata M, Kadomatsu T, Fukuhara S, Miyata K, Ito Y, Endo M, Urano T, Zhu HJ, Tsukano H, Tazume H, et al. 2009. Angiopoietin-like protein 2 promotes chronic adipose tissue inflammation and obesity-related systemic insulin resistance. Cell Metab 10: 178-188. doi:10.1016/j.cmet.2009.08.003

Tian Z, Miyata K, Kadomatsu T, Horiguchi H, Fukushima H, Tohyama S, Ujihara Y, Okumura T, Yamaguchi S, Zhao J, et al. 2016. ANGPTL2 activity in cardiac pathologies accelerates heart failure by perturbing cardiac function and energy metabolism. Nat Commun 7: 13016. doi:10.1038/ ncomms13016

Toiyama Y, Tanaka K, Kitajima T, Shimura T, Kawamura M, Kawamoto A, Okugawa Y, Saigusa S, Hiro J, Inoue Y, et al. 2014. Elevated serum angiopoietin-like protein 2 correlates with the metastatic properties of colorectal cancer: a serum biomarker for early diagnosis and recurrence. Clin Cancer Res 20: 6175-6186. doi:10.1158/1078-0432.CCR-14-0007

Ujike A, Takeda K, Nakamura A, Ebihara S, Akiyama K, Takai T. 2002. Impaired dendritic cell maturation and increased TH2 responses in PIR-B ${ }^{-/}$mice. Nat Immunol 3: 542-548. doi:10 $.1038 /$ ni801

Yoshinaga $\mathrm{T}$, Shigemitsu $\mathrm{T}$, Nishimata $\mathrm{H}$, Kitazono $\mathrm{M}$, Hori E, Tomiyoshi A, Takei T, Yoshida M. 2015. Angiopoietin-like protein 2 as a potential biomarker for colorectal cancer. Mol Clin Oncol 3: 1080-1084. doi:10.3892/mco.2015.577

Yoshinaga T, Niou T, Niihara T, Kajiya Y, Hori E, Tomiyoshi A, Tokudome E, Nishimata H, Takei T, Yoshida M. 2018. Angiopoietin-like protein 2 is a useful biomarker for pancreatic cancer that is associated with type 2 diabetes mellitus and inflammation. J Cancer 9: 4736-4741. doi:10.7150/jca.25404

Yugami M, Odagiri H, Endo M, Tsutsuki H, Fujii S, Kadomatsu T, Masuda T, Miyata K, Terada K, Tanoue H, et al. 2016. Mice deficient in angiopoietin-like protein 2 (Angpt12) gene show increased susceptibility to bacterial infection due to attenuated macrophage activity. I Biol Chem 291: 1884318852. doi:10.1074/jbc.M116.720870

Zheng J, Umikawa M, Cui C, Li J, Chen X, Zhang C, Huynh H, Kang X, Silvany R, Wan X, et al. 2012. Inhibitory receptors bind ANGPTLs and support blood stem cells and leukaemia development. Nature 485: 656-660. doi:10.1038/nature11095 


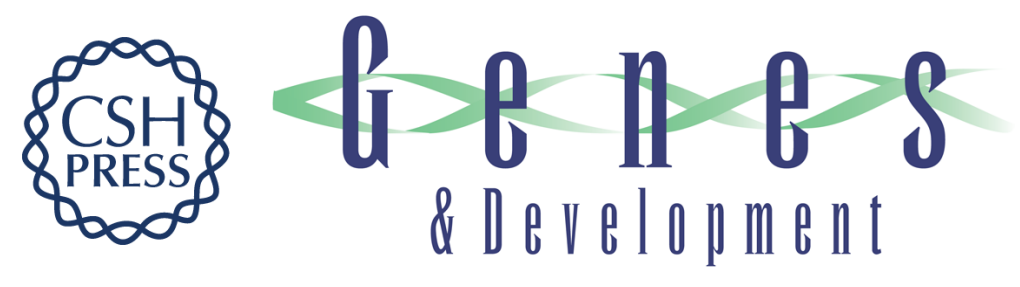

\section{Dual functions of angiopoietin-like protein 2 signaling in tumor progression and anti-tumor immunity}

Haruki Horiguchi, Tsuyoshi Kadomatsu, Ryoma Kurahashi, et al.

Genes Dev. 2019, 33: originally published online November 14, 2019

Access the most recent version at doi:10.1101/gad.329417.119

\section{Supplemental} Material

References

Creative

Commons

License

Email Alerting

Service
http://genesdev.cshlp.org/content/suppl/2019/11/11/gad.329417.119.DC1

This article cites 69 articles, 19 of which can be accessed free at:

http://genesdev.cshlp.org/content/33/23-24/1641.full.html\#ref-list-1

This article is distributed exclusively by Cold Spring Harbor Laboratory Press for the first six months after the full-issue publication date (see

http://genesdev.cshlp.org/site/misc/terms.xhtml). After six months, it is available under a Creative Commons License (Attribution-NonCommercial 4.0 International), as described at http://creativecommons.org/licenses/by-nc/4.0/.

Receive free email alerts when new articles cite this article - sign up in the box at the top right corner of the article or click here.

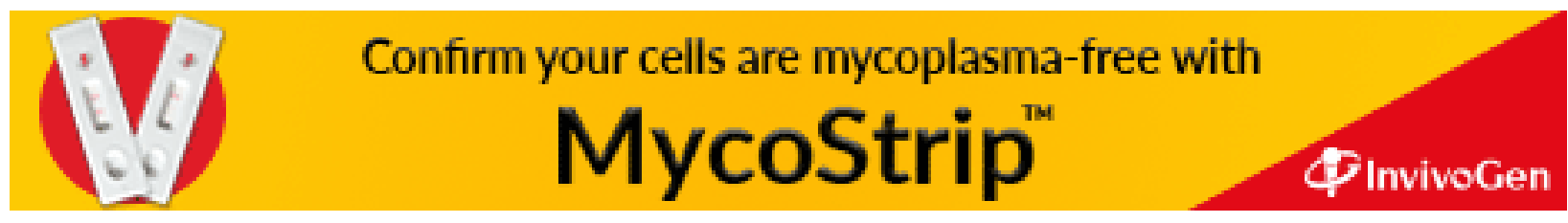

